FEDERAL RESERVE BANK OF SAN FRANCISCO

WORKING PAPER SERIES

\title{
Can Spanned Term Structure Factors Drive Stochastic Yield Volatility?
}

\author{
Jens H. E. Christensen, \\ Federal Reserve Bank of San Francisco \\ Jose A. Lopez. \\ Federal Reserve Bank of San Francisco \\ Glenn D. Rudebusch \\ Federal Reserve Bank of San Francisco
}

January 2014

Working Paper 2014-03

http://www.frbsf.org/economic-research/publications/working-papers/wp2014-03.pdf

The views in this paper are solely the responsibility of the authors and should not be interpreted as reflecting the views of the Federal Reserve Bank of San Francisco or the Board of Governors of the Federal Reserve System. 


\title{
Can Spanned Term Structure Factors Drive Stochastic Yield Volatility? ${ }^{\dagger}$
}

\author{
Jens H. E. Christensen \\ Jose A. Lopez \\ Glenn D. Rudebusch \\ Federal Reserve Bank of San Francisco \\ 101 Market Street, Mailstop 1130 \\ San Francisco, CA 94105
}

\begin{abstract}
The ability of the usual factors from empirical arbitrage-free representations of the term structure - that is, spanned factors - to account for interest rate volatility dynamics has been much debated. We examine this issue with a comprehensive set of new arbitrage-free term structure specifications that allow for spanned stochastic volatility to be linked to one or more of the yield curve factors. Using U.S. Treasury yields, we find that much realized stochastic volatility cannot be associated with spanned term structure factors. However, a simulation study reveals that the usual realized volatility metric is misleading when yields contain plausible measurement noise. We argue that other metrics should be used to validate stochastic volatility models.
\end{abstract}

JEL Classification: C51, C52, E43, G12.

Keywords: arbitrage-free Nelson-Siegel model, term structure modeling, interest rate risk, model validation.

\footnotetext{
${ }^{\dagger}$ We thank participants at the FRB Atlanta Day Ahead Conference for helpful comments, especially our discussant Gregory Duffee. We also thank participants at the Humboldt-Copenhagen Conference 2009, the FDIC's 19th Annual Derivatives Securities \& Risk Management Conference, and the EFMA 2010 Annual meeting as well as seminar participants at the Copenhagen Business School and the Swiss Finance Institute for helpful comments on earlier drafts. A special thank goes to Mikhail Chernov for helpful comments and suggestions. The views in this paper are solely the responsibility of the authors and should not be interpreted as reflecting the views of the Federal Reserve Bank of San Francisco or the Board of Governors of the Federal Reserve System.

Draft date: January 16, 2014.
} 


\section{Introduction}

Understanding and predicting the variability of interest rates play a crucial role in derivatives pricing and portfolio risk management, so creating accurate empirical models of interest rate stochastic volatility has been a key research priority. Unfortunately, while the canonical affine arbitrage-free term structure models have been widely applied to price bonds, the ability of these popular models to capture the changing volatility of interest rates has been seriously questioned. Indeed, using U.S. swap rate data, Collin-Dufresne, Goldstein, and Jones (2009) find that a standard three-factor affine model, in which one of the factors drives volatility, produces very poor volatility estimates. They suggest that an unspanned volatility factor (i.e., a factor that affects interest rate volatility without changing bond prices) has to be added to the affine term structure model in order to capture the stochastic volatility observed in U.S. dollar swap rates. However, Jacobs and Karoui (2009) argue this conclusion is sensitive to the specific sample period analyzed, and they recommend further research to examine whether spanned factors in an affine arbitrage-free model can capture the conditional volatility in U.S. Treasury and swap rate data. In this paper, we conduct such research by examining to what extent spanned factors can generate stochastic interest rate volatility.

We incorporate spanned stochastic volatility into the class of affine, arbitrage-free NelsonSiegel (AFNS) term structure models developed by Christensen, Diebold, and Rudebusch (2011, henceforth CDR). ${ }^{1}$ These models are characterized by imposing the level, slope, and curvature factor structure observed in the usual principal components analysis of the yield curve. This class of models captures both the cross section of yields and their time-series dynamics quite well and can be readily estimated. ${ }^{2}$ Indeed, in previous work, analysis of multiple factor sources for spanned volatility have been hampered by problems in estimating the parameters of multifactor affine models. ${ }^{3}$ However, we estimate new specifications of AFNS models that allow one, two, or all three factors to generate spanned stochastic volatility. A key advantage of our approach to modeling stochastic volatility is that the factors remain well-defined as level, slope, and curvature for any admissible parameter set despite their latent

\footnotetext{
${ }^{1}$ In related work, Hautsch and $\mathrm{Ou}(2012)$ and Koopman, Malle, and van der Wel (2010) incorporate stochastic volatility into a dynamic Nelson-Siegel model that — unlike in our work - does not address the problem of eliminating the existence of arbitrage opportunities

${ }^{2}$ This model has been shown to exhibit both good in-sample fit and out-of-sample forecast accuracy for various yield curves. The empirical analysis conducted in CDR is based on unsmoothed Fama-Bliss data for nominal Treasury yields, while Christensen and Rudebusch (2012) analyze the same Treasury yields used in this paper. Christensen, Lopez, and Rudebusch (2010) examine yields for nominal and real Treasuries, while Christensen, Lopez, and Rudebusch (2014) examine short-term LIBOR and highly-rated financial firms' corporate bond rates.

${ }^{3}$ The latent nature of the factors and the over-parameterization of the models make estimation quite difficult. See CDR and Duffee (2011).
} 
nature. This structure also makes the results comparable across model classes and allows us to detail which factors are able to generate empirically plausible stochastic yield volatility. This feature distinguishes our approach from the existing literature on affine models where the optimal parameters for any unconstrained affine model only implicitly reveal which factor(s) generate(s) stochastic volatility.

We estimate these new models on daily U.S. Treasury yields from January 2, 1985, to June 30, 2011, for eight maturities. We find that the introduction of stochastic volatility does not weaken the models' in-sample fit of the term structure relative to a model with constant volatility. Following the existing literature, we correlate the models' predicted stochastic volatility (measured in terms of standard deviations) with a measure of realized standard deviations based on daily data. As in Collin-Dufresne et. (2009), we find that the correlation between the predicted and realized bond yield standard deviations is quite low and often negative over the full sample. However, we also provide evidence that this negative result is not definitive. In particular, we construct a simulation experiment in which all yield volatility is spanned by construction. We find that the predicted yield volatilities generated from model estimations on the simulated data have correlations with the simulated data's realized yield volatilities that depend critically on the quality of the data. If measurement noise is unrealistically low (i.e., normal i.i.d. errors with one basis point standard deviation or lower), the correlations are quite high as theory would suggest (e.g., Andersen, Bollerslev, Diebold, and Labys 2003). On the other hand, if the added white noise is of the size of the fitted errors in our model estimations, then the correlations are frequently low, and occasionally even negative. Based on this evidence, we conclude that correlations at high frequency between ex ante predicted and ex post realized yield volatility measures are flawed measures for validating term structure models with stochastic volatility - contrary to the conclusions of Andersen and Benzoni (2010) and Collin-Dufresne et. (2009).

As a consequence of the shortcomings of the realized volatility metric, we try to validate our stochastic volatility AFNS models along other dimensions. First, instead of focusing on time-series correlations at high frequency, we examine the root-mean-squared errors (RMSE) between the predicted and realized yield standard deviations. These model validation results are more favorable to affine models with spanned volatility factors. In particular, the AFNS model in which all three factors can affect volatility performs well based on this measure with RMSEs below 15 basis points at all maturities in addition to providing a good fit to the cross section of yields. Second, this model is also able to match the unconditional mean and standard deviation of our realized yield volatility series. To summarize, our results show that, 
while incapable of matching the high-frequency time variation of realized yield volatilities, three-factor affine models can fit the cross section of yields and capture an interesting part of realized yield volatility.

The rest of the paper is structured as follows. Section 2 presents a short summary of the original AFNS model of the term structure with constant volatility. Section 3 introduces the modified classes of AFNS models with stochastic volatility dynamics. Section 4 presents empirical results for the AFNS model classes, while Section 5 studies their ability to capture stochastic yield volatility. Finally, Section 6 concludes.

\section{The AFNS Model with Constant Volatility}

In this section, we briefly review the AFNS model with constant volatility, throughout referred to as the $\mathrm{AFNS}_{0}$ specification. ${ }^{4}$ A standard continuous-time affine arbitrage-free structure (Duffie and Kan 1996) underlies all the models in this paper. To represent an affine diffusion process, define a filtered probability space $\left(\Omega, \mathcal{F},\left(\mathcal{F}_{t}\right), Q\right)$, where the filtration $\left(\mathcal{F}_{t}\right)=\left\{\mathcal{F}_{t}\right.$ : $t \geq 0\}$ satisfies the usual conditions; see Williams (1997). The state variable $X_{t}$ is assumed to be a Markov process defined on a set $M \subset \mathbf{R}^{n}$ that solves the following stochastic differential equation (SDE):

$$
d X_{t}=K^{Q}(t)\left[\theta^{Q}(t)-X_{t}\right] d t+\Sigma(t) D\left(X_{t}, t\right) d W_{t}^{Q},
$$

where $W^{Q}$ is a standard Brownian motion in $\mathbf{R}^{n}$, the information of which is contained in the filtration $\left(\mathcal{F}_{t}\right) .^{5}$ The drift terms $\theta^{Q}:[0, T] \rightarrow \mathbf{R}^{n}$ and $K^{Q}:[0, T] \rightarrow \mathbf{R}^{n \times n}$ are bounded, continuous functions. ${ }^{6}$ Similarly, the volatility matrix $\Sigma:[0, T] \rightarrow \mathbf{R}^{n \times n}$ is assumed to be a bounded, continuous function, while $D: M \times[0, T] \rightarrow \mathbf{R}^{n \times n}$ is assumed to have the following diagonal structure:

$$
\left(\begin{array}{ccc}
\sqrt{\gamma^{1}(t)+\delta^{1}(t) X_{t}} & \cdots & 0 \\
\vdots & \ddots & \vdots \\
0 & \cdots & \sqrt{\gamma^{n}(t)+\delta^{n}(t) X_{t}}
\end{array}\right)
$$

\footnotetext{
${ }^{4}$ Our nomenclature draws on Dai and Singleton (2000). Our $\operatorname{AFNS}_{n}$ models are members of their $A_{n}(3)$ class of models, which have three state variables and $n$ square-root processes.

${ }^{5}$ Note that the affine property applies to bond prices; therefore, affine models only impose structure on the factor dynamics under the pricing measure.

${ }^{6}$ Stationarity of the state variables is ensured if all the eigenvalues of $K^{Q}(t)$ are positive. If the eigenvalues are complex, the real component should be positive; see Ahn, Dittmar, and Gallant (2002). However, stationarity is not a necessary requirement for the process to be well defined.
} 
where

$$
\gamma(t)=\left(\begin{array}{c}
\gamma^{1}(t) \\
\vdots \\
\gamma^{n}(t)
\end{array}\right), \quad \delta(t)=\left(\begin{array}{ccc}
\delta_{1}^{1}(t) & \ldots & \delta_{n}^{1}(t) \\
\vdots & \ddots & \vdots \\
\delta_{1}^{n}(t) & \ldots & \delta_{n}^{n}(t)
\end{array}\right)
$$

$\gamma:[0, T] \rightarrow \mathbf{R}^{n}$ and $\delta:[0, T] \rightarrow \mathbf{R}^{n \times n}$ are bounded, continuous functions, and $\delta^{i}(t)$ denotes the $i$ th row of the $\delta(t)$-matrix. Finally, the instantaneous risk-free rate is assumed to be an affine function of the state variables

$$
r_{t}=\rho_{0}(t)+\rho_{1}(t)^{\prime} X_{t}
$$

where $\rho_{0}:[0, T] \rightarrow \mathbf{R}$ and $\rho_{1}:[0, T] \rightarrow \mathbf{R}^{n}$ are bounded, continuous functions.

Duffie and Kan (1996) prove that zero-coupon bond prices in this framework are exponentialaffine functions of the state variables

$$
P(t, T)=E_{t}^{Q}\left[\exp \left(-\int_{t}^{T} r_{u} d u\right)\right]=\exp \left(B(t, T)^{\prime} X_{t}+A(t, T)\right)
$$

where $B(t, T)$ and $A(t, T)$ are the solutions to the following system of ordinary differential equations (ODEs)

$$
\begin{aligned}
& \frac{d B(t, T)}{d t}=\rho_{1}+\left(K^{Q}\right)^{\prime} B(t, T)-\frac{1}{2} \sum_{j=1}^{n}\left(\Sigma^{\prime} B(t, T) B(t, T)^{\prime} \Sigma\right)_{j, j}\left(\delta^{j}\right)^{\prime}, \quad B(T, T)=0, \\
& \frac{d A(t, T)}{d t}=\rho_{0}-B(t, T)^{\prime} K^{Q} \theta^{Q}-\frac{1}{2} \sum_{j=1}^{n}\left(\Sigma^{\prime} B(t, T) B(t, T)^{\prime} \Sigma\right)_{j, j} \gamma^{j}, \quad A(T, T)=0,
\end{aligned}
$$

and the possible time-dependence of the parameters is suppressed in the notation. These pricing functions imply that the zero-coupon yields are given by affine functions of $X_{t}$

$$
y(t, T)=-\frac{1}{T-t} \log P(t, T)=-\frac{B(t, T)^{\prime}}{T-t} X_{t}-\frac{A(t, T)}{T-t} .
$$

In the AFNS model with constant volatility, the instantaneous risk-free rate is defined by

$$
r_{t}=X_{t}^{1}+X_{t}^{2}
$$

In addition, the three state variables in the model $X_{t}=\left(X_{t}^{1}, X_{t}^{2}, X_{t}^{3}\right)$ are described by the 
following system of SDEs under the risk-neutral $Q$-measure: ${ }^{7}$

$$
\left(\begin{array}{c}
d X_{t}^{1} \\
d X_{t}^{2} \\
d X_{t}^{3}
\end{array}\right)=\left(\begin{array}{ccc}
0 & 0 & 0 \\
0 & \lambda & -\lambda \\
0 & 0 & \lambda
\end{array}\right)\left[\left(\begin{array}{c}
\theta_{1}^{Q} \\
\theta_{2}^{Q} \\
\theta_{3}^{Q}
\end{array}\right)-\left(\begin{array}{c}
X_{t}^{1} \\
X_{t}^{2} \\
X_{t}^{3}
\end{array}\right)\right] d t+\Sigma\left(\begin{array}{c}
d W_{t}^{1, Q} \\
d W_{t}^{2, Q} \\
d W_{t}^{3, Q}
\end{array}\right), \quad \lambda>0 .
$$

In matrix notation, this system is denoted as

$$
d X_{t}=K^{Q}\left(\theta^{Q}-X_{t}\right) d t+\Sigma^{Q} d W_{t}^{Q} .
$$

CDR show that this specification implies that zero-coupon bond yields are given by

$$
y(t, T)=X_{t}^{1}+\left(\frac{1-e^{-\lambda(T-t)}}{\lambda(T-t)}\right) X_{t}^{2}+\left(\frac{1-e^{-\lambda(T-t)}}{\lambda(T-t)}-e^{-\lambda(T-t)}\right) X_{t}^{3}-\frac{A(t, T)}{T-t} .
$$

Importantly, the three factors in this yield function have level, slope, and curvature loadings identical to those in the popular Nelson and Siegel (1987) yield curve, while the final yieldadjustment term captures convexity effects due to Jensen's inequality and ensures the absence of arbitrage.

The model is completed with a risk premium specification that connects the factor dynamics to the dynamics under the real-world (or historical) $P$-measure. It is important to note that there are no restrictions on the dynamic drift components under the empirical $P$-measure beyond the requirement of constant volatility. To facilitate empirical implementation, we use the extended affine risk premium developed by Cheridito, Filipović, and Kimmel (2007). In the Gaussian framework, this specification implies that the risk premiums $\Gamma_{t}$ depend on the state variables; that is,

$$
\Gamma_{t}=\gamma^{0}+\gamma^{1} X_{t}
$$

where $\gamma^{0} \in \mathbf{R}^{3}$ and $\gamma^{1} \in \mathbf{R}^{3 \times 3}$ contain unrestricted parameters. ${ }^{8}$ The relationship between real-world yield curve dynamics under the $P$-measure and risk-neutral dynamics under the $Q$-measure is given by

$$
d W_{t}^{Q}=d W_{t}^{P}+\Gamma_{t} d t
$$

\footnotetext{
${ }^{7}$ As discussed in CDR, with a unit root in the level factor under the pricing measure, the model is not arbitrage-free with an unbounded horizon; therefore, as is often done in theoretical discussions, we impose an arbitrary maximum horizon.

${ }^{8}$ For Gaussian models this specification is equivalent to the essentially affine risk premium specification introduced in Duffee (2002).
} 
Thus, the $P$-dynamics of the state variables are

$$
d X_{t}=K^{P}\left(\theta^{P}-X_{t}\right) d t+\Sigma d W_{t}^{P}
$$

where both $K^{P}$ and $\theta^{P}$ are allowed to vary freely relative to their counterparts under the $Q$-measure.

The main limitation of the AFNS class of models above is the constant volatility matrix $\Sigma$. The purpose of this paper is to modify the AFNS model in a straightforward fashion in order to incorporate stochastic volatility. The key assumption to preserving the desirable Nelson-Siegel factor loading structure in the zero-coupon bond yield function is to maintain the $K^{Q}$ mean-reversion matrix under the $Q$-measure. Furthermore, all model classes will be characterized by an instantaneous risk-free rate defined as the sum of the first two factors

$$
r_{t}=X_{t}^{1}+X_{t}^{2}
$$

\section{Three AFNS Specifications with Stochastic Volatility}

In this section, we introduce three new AFNS specifications with stochastic volatility. These three specifications vary depending on whether they contain one, two, or three stochastic volatility factors and on the identity of those factors. For each model class, we derive the maximally flexible specification available using the extended affine risk premium specification.

\subsection{AFNS Models with One Stochastic Volatility Factor}

There are two AFNS stochastic volatility specifications that allow just one factor to exhibit stochastic volatility. The first, denoted as the $\mathrm{AFNS}_{1}$-L model, allows only the level factor to exhibit stochastic volatility. The state variables in this specification follow this system of stochastic differential equations under the risk-neutral $Q$-measure:

$$
\begin{aligned}
\left(\begin{array}{c}
d X_{t}^{1} \\
d X_{t}^{2} \\
d X_{t}^{3}
\end{array}\right) & =\left(\begin{array}{ccc}
\varepsilon & 0 & 0 \\
0 & \lambda & -\lambda \\
0 & 0 & \lambda
\end{array}\right)\left[\left(\begin{array}{c}
\theta_{1}^{Q} \\
\theta_{2}^{Q} \\
\theta_{3}^{Q}
\end{array}\right)-\left(\begin{array}{c}
X_{t}^{1} \\
X_{t}^{2} \\
X_{t}^{3}
\end{array}\right)\right] d t \\
& +\left(\begin{array}{ccc}
\sigma_{11} & 0 & 0 \\
\sigma_{21} & \sigma_{22} & 0 \\
\sigma_{31} & \sigma_{32} & \sigma_{33}
\end{array}\right)\left(\begin{array}{ccc}
\sqrt{X_{t}^{1}} & 0 \\
0 & \sqrt{1+\beta_{21} X_{t}^{1}} & 0 \\
0 & 0 & \sqrt{1+\beta_{31} X_{t}^{1}}
\end{array}\right)\left(\begin{array}{c}
d W_{t}^{1, Q} \\
d W_{t}^{2, Q} \\
d W_{t}^{3, Q}
\end{array}\right),
\end{aligned}
$$


where the $X_{t}^{1}$ level factor is a square-root process with stochastic volatility that affects the instantaneous volatility of the two other factors through the $\beta_{21}$ and $\beta_{31}$ volatility sensitivity parameters. 9

For the factor loadings in the zero-coupon bond prices, $B^{1}(t, T)$ is the solution to

$$
\begin{aligned}
\frac{d B^{1}(t, T)}{d t}= & 1+\varepsilon B^{1}(t, T)-\frac{1}{2} \sigma_{11}^{2} B^{1}(t, T)^{2}-\frac{1}{2} \sigma_{21}^{2} B^{2}(t, T)^{2}-\frac{1}{2} \sigma_{31}^{2} B^{3}(t, T)^{2} \\
& -\sigma_{21} \sigma_{11} B^{1}(t, T) B^{2}(t, T)-\sigma_{31} \sigma_{11} B^{1}(t, T) B^{3}(t, T)-\sigma_{21} \sigma_{31} B^{2}(t, T) B^{3}(t, T) \\
& -\frac{1}{2} \beta_{21}\left[\sigma_{22}^{2} B^{2}(t, T)^{2}+\sigma_{32}^{2} B^{3}(t, T)^{2}+2 \sigma_{22} \sigma_{32} B^{2}(t, T) B^{3}(t, T)\right]-\frac{1}{2} \beta_{31} \sigma_{33}^{2} B^{3}(t, T)^{2},
\end{aligned}
$$

while $B^{2}(t, T)$ and $B^{3}(t, T)$ are given by

$$
\begin{aligned}
& B^{2}(t, T)=-\left(\frac{1-e^{-\lambda(T-t)}}{\lambda}\right) \\
& B^{3}(t, T)=(T-t) e^{-\lambda(T-t)}-\left(\frac{1-e^{-\lambda(T-t)}}{\lambda}\right) .
\end{aligned}
$$

The last two factor loadings match exactly the factor loadings of the slope and curvature factors in the Nelson-Siegel zero-coupon yield function, while the ODE for $B^{1}(t, T)$ contains quadratic elements related to the stochastic volatility of $X_{t}^{1}$. The $A(t, T)$-function in the yield-adjustment term in this class of models must solve the following ODE:

$$
\frac{d A(t, T)}{d t}=-B(t, T)^{\prime} K^{Q} \theta^{Q}-\frac{1}{2} \sigma_{22}^{2} B^{2}(t, T)^{2}-\frac{1}{2}\left(\sigma_{32}^{2}+\sigma_{33}^{2}\right) B^{3}(t, T)^{2}-\sigma_{22} \sigma_{32} B^{2}(t, T) B^{3}(t, T) .
$$

To estimate this model, we specify the dynamics under the real-world $P$-measure as the measure change $d W^{Q}=d W_{t}^{P}+\Gamma_{t} d t$. Given the extended affine risk premium specification, the maximally flexible affine $P$-dynamics are, in general, given by

$$
\begin{aligned}
\left(\begin{array}{c}
d X_{t}^{1} \\
d X_{t}^{2} \\
d X_{t}^{3}
\end{array}\right) & =\left(\begin{array}{ccc}
\kappa_{11}^{P} & 0 & 0 \\
\kappa_{21}^{P} & \kappa_{22}^{P} & \kappa_{23}^{P} \\
\kappa_{31}^{P} & \kappa_{32}^{P} & \kappa_{33}^{P}
\end{array}\right)\left[\left(\begin{array}{c}
\theta_{1}^{P} \\
\theta_{2}^{P} \\
\theta_{3}^{P}
\end{array}\right)-\left(\begin{array}{c}
X_{t}^{1} \\
X_{t}^{2} \\
X_{t}^{3}
\end{array}\right)\right] d t \\
& +\left(\begin{array}{ccc}
\sigma_{11} & 0 & 0 \\
\sigma_{21} & \sigma_{22} & 0 \\
\sigma_{31} & \sigma_{32} & \sigma_{33}
\end{array}\right)\left(\begin{array}{ccc}
\sqrt{X_{t}^{1}} & 0 & 0 \\
0 & \sqrt{1+\beta_{21} X_{t}^{1}} & 0 \\
0 & 0 & \sqrt{1+\beta_{31} X_{t}^{1}}
\end{array}\right)\left(\begin{array}{c}
d W_{t}^{1, P} \\
d W_{t}^{2, P} \\
d W_{t}^{3, P}
\end{array}\right) .
\end{aligned}
$$

\footnotetext{
${ }^{9}$ Note that we cannot set $\kappa_{11}^{Q}$ to zero as that would eliminate the drift of $X_{t}^{1}$ and cause this process to remain at zero once it hits zero, which it will $P$-a.s. when $\kappa_{11}^{Q}=0$. Instead, we fix this parameter at a small, but positive, $\varepsilon=10^{-6}$, to get close to the unit-root property imposed in the $\mathrm{AFNS}_{0}$ model.
} 
To ensure absence of arbitrage as per Cheridito et al. (2007), the constrained $X_{t}^{1}$ squareroot process must satisfy a Feller condition under both probability measures; i.e.,

$$
\kappa_{11}^{P} \theta_{1}^{P}>\frac{1}{2} \sigma_{11}^{2} \quad \text { and } \quad \varepsilon \theta_{1}^{Q}>\frac{1}{2} \sigma_{11}^{2}
$$

These restrictions ensure that the $X_{t}^{1}$-process will remain in positive territory.

Finally, we identify this class of models by fixing $\theta_{2}^{Q}=\theta_{3}^{Q}=0$, eliminating the $Q$-means of the unconstrained processes as in CDR. These restrictions allow the corresponding means under the $P$-measure to be determined in the estimation. There are 20 parameters in the maximally flexible specification of this class of models.

The natural next AFNS one-factor stochastic volatility specification would allow the slope factor to exhibit stochastic volatility. However, examination of the matrix

$$
K^{Q}=\left(\begin{array}{ccc}
0 & 0 & 0 \\
0 & \lambda & -\lambda \\
0 & 0 & \lambda
\end{array}\right),
$$

shows that $X_{t}^{2}$ cannot be a square-root process with $X_{t}^{3}$ as an unconstrained process, if the important off-diagonal element $\kappa_{23}^{Q}$ is to remain equal to $-\lambda$, which generates the unique factor loading of the curvature factor in the AFNS model. Thus, there is no admissible $\mathrm{AFNS}_{1}$ $\mathrm{S}$ model. The $\mathrm{AFNS}_{1}$-C model, which allows for a stochastic volatility curvature factor, is admissible. However, empirically, this specification turns out to be little different from the Gaussian $\mathrm{AFNS}_{0}$ model, so we omit it from our discussion here though model details are available from the authors.

\subsection{AFNS Models with Two Stochastic Volatility Factors}

Our second class of stochastic volatility models allows for two stochastic volatility factors. Although there are three potential specifications, the specification with just the level and slope factors exhibiting stochastic volatility is not admissible because it does not permit the important off-diagonal element $\kappa_{23}^{Q}$ to equal $-\lambda$, which is the unique characteristic of the curvature factor in the original AFNS model. Instead, stochastic volatility is associated with either level and curvature or slope and curvature. One of these specifications, denoted $\mathrm{AFNS}_{2^{-}}$ $\mathrm{LC}$, is similar empirically to the $\mathrm{AFNS}_{1}$-L model, so, for brevity, it is omitted - though model details are available from the authors.

The AFNS specification with two volatility factors that we focus on allows the slope and 
curvature factors to be square-root processes while the level factor remains unconstrained. The factor dynamics of this $\mathrm{AFNS}_{2}$-SC model under the $Q$-measure are

$$
\begin{aligned}
\left(\begin{array}{c}
d X_{t}^{1} \\
d X_{t}^{2} \\
d X_{t}^{3}
\end{array}\right) & =\left(\begin{array}{ccc}
0 & 0 & 0 \\
0 & \lambda & -\lambda \\
0 & 0 & \lambda
\end{array}\right)\left[\left(\begin{array}{c}
\theta_{1}^{Q} \\
\theta_{2}^{Q} \\
\theta_{3}^{Q}
\end{array}\right)-\left(\begin{array}{c}
X_{t}^{1} \\
X_{t}^{2} \\
X_{t}^{3}
\end{array}\right)\right] d t \\
& +\left(\begin{array}{ccc}
\sigma_{11} & \sigma_{12} & \sigma_{13} \\
0 & \sigma_{22} & 0 \\
0 & 0 & \sigma_{33}
\end{array}\right)\left(\begin{array}{ccc}
\sqrt{1+\beta_{12} X_{t}^{2}+\beta_{13} X_{t}^{3}} & 0 & 0 \\
0 & \sqrt{X_{t}^{2}} & 0 \\
0 & 0 & \sqrt{X_{t}^{3}}
\end{array}\right)\left(\begin{array}{c}
d W_{t}^{1, Q} \\
d W_{t}^{2, Q} \\
d W_{t}^{3, Q}
\end{array}\right) .
\end{aligned}
$$

Note that the $X_{t}^{2}$ and $X_{t}^{3}$ square-root processes are positively correlated through the offdiagonal element $\kappa_{23}^{Q}=-\lambda<0$. Beyond generating their own stochastic volatility, these two factors induce instantaneous volatility for $X_{t}^{1}$ via the $\beta_{12}$ and $\beta_{13}$ volatility sensitivities.

For the first factor loading in the zero-coupon bond price function, this structure implies that

$$
B^{1}(t, T)=-(T-t)
$$

which preserves the role of the level factor. The next two factor loadings are the unique solutions to:

$$
\begin{aligned}
\frac{d B^{2}(t, T)}{d t}= & 1+\lambda B^{2}(t, T)-\frac{1}{2} \sigma_{22}^{2} B^{2}(t, T)^{2}-\frac{1}{2} \sigma_{12}^{2} B^{1}(t, T)^{2} \\
& -\sigma_{12} \sigma_{22} B^{1}(t, T) B^{2}(t, T)-\frac{1}{2} \beta_{12} \sigma_{11}^{2} B^{1}(t, T)^{2} \\
\frac{d B^{3}(t, T)}{d t}= & -\lambda B^{2}(t, T)+\lambda B^{3}(t, T)-\frac{1}{2} \sigma_{33}^{2} B^{3}(t, T)^{2}-\frac{1}{2} \sigma_{13}^{2} B^{1}(t, T)^{2} \\
& -\sigma_{13} \sigma_{33} B^{1}(t, T) B^{3}(t, T)-\frac{1}{2} \beta_{13} \sigma_{11}^{2} B^{1}(t, T)^{2}
\end{aligned}
$$

The $A(t, T)$-function in the yield-adjustment term is the solution to

$$
\frac{d A(t, T)}{d t}=-B(t, T)^{\prime} K^{Q} \theta^{Q}-\frac{1}{2} \sigma_{11}^{2} B^{1}(t, T)^{2} .
$$

Using the extended affine risk premium specification, the maximally flexible affine $P$ - 
dynamics can be written as

$$
\begin{aligned}
\left(\begin{array}{l}
d X_{t}^{1} \\
d X_{t}^{2} \\
d X_{t}^{3}
\end{array}\right) & =\left(\begin{array}{ccc}
\kappa_{11}^{P} & \kappa_{12}^{P} & \kappa_{13}^{P} \\
0 & \kappa_{22}^{P} & \kappa_{23}^{P} \\
0 & \kappa_{32}^{P} & \kappa_{33}^{P}
\end{array}\right)\left[\left(\begin{array}{c}
\theta_{1}^{P} \\
\theta_{2}^{P} \\
\theta_{3}^{P}
\end{array}\right)-\left(\begin{array}{c}
X_{t}^{1} \\
X_{t}^{2} \\
X_{t}^{3}
\end{array}\right)\right] d t \\
& +\left(\begin{array}{ccc}
\sigma_{11} & \sigma_{12} & \sigma_{13} \\
0 & \sigma_{22} & 0 \\
0 & 0 & \sigma_{33}
\end{array}\right)\left(\begin{array}{ccc}
\sqrt{1+\beta_{12} X_{t}^{2}+\beta_{13} X_{t}^{3}} & 0 & 0 \\
0 & \sqrt{X_{t}^{2}} & 0 \\
0 & 0 & \sqrt{X_{t}^{3}}
\end{array}\right)\left(\begin{array}{c}
d W_{t}^{1, P} \\
d W_{t}^{2, P} \\
d W_{t}^{3, P}
\end{array}\right) .
\end{aligned}
$$

To keep this class of models arbitrage-free, the $X_{t}^{2}$ and $X_{t}^{3}$ factors must avoid hitting the zero-boundary. This outcome is ensured by imposing the Feller condition on their parameters as follows:

$\kappa_{22}^{P} \theta_{2}^{P}+\kappa_{23}^{P} \theta_{3}^{P}>\frac{1}{2} \sigma_{22}^{2} ; \quad \lambda \theta_{2}^{Q}-\lambda \theta_{3}^{Q}>\frac{1}{2} \sigma_{22}^{2} ; \quad \kappa_{33}^{P} \theta_{3}^{P}+\kappa_{32}^{P} \theta_{2}^{P}>\frac{1}{2} \sigma_{33}^{2} ; \quad$ and $\quad \lambda \theta_{3}^{Q}>\frac{1}{2} \sigma_{33}^{2}$.

Furthermore, for $X_{t}^{2}$ and $X_{t}^{3}$ to be well-defined, the sign of the effect they have on each other must be positive, which we impose using the constraints $\kappa_{23}^{P} \leq 0$ and $\kappa_{32}^{P} \leq 0$. This implies that the two square-root processes cannot be negatively correlated. Finally, we identify this class of models by fixing $\theta_{1}^{Q}=0$, which allows $\theta^{P}$ to vary freely. In total, there are 20 free parameters in the maximally flexible specification.

\section{3 $\quad$ AFNS Models with Three Stochastic Volatility Factors}

In the $\mathrm{AFNS}_{3}$ specification, all three factors exhibit stochastic volatility. The dynamics of $X_{t}$ are described under the $Q$-measure as ${ }^{10}$

$$
\begin{aligned}
\left(\begin{array}{c}
d X_{t}^{1} \\
d X_{t}^{2} \\
d X_{t}^{3}
\end{array}\right) & =\left(\begin{array}{ccc}
\varepsilon & 0 & 0 \\
0 & \lambda & -\lambda \\
0 & 0 & \lambda
\end{array}\right)\left[\left(\begin{array}{c}
\theta_{1}^{Q} \\
\theta_{2}^{Q} \\
\theta_{3}^{Q}
\end{array}\right)-\left(\begin{array}{c}
X_{t}^{1} \\
X_{t}^{2} \\
X_{t}^{3}
\end{array}\right)\right] d t \\
& +\left(\begin{array}{ccc}
\sigma_{11} & 0 & 0 \\
0 & \sigma_{22} & 0 \\
0 & 0 & \sigma_{33}
\end{array}\right)\left(\begin{array}{ccc}
\sqrt{X_{t}^{1}} & 0 & 0 \\
0 & \sqrt{X_{t}^{2}} & 0 \\
0 & 0 & \sqrt{X_{t}^{3}}
\end{array}\right)\left(\begin{array}{c}
d W_{t}^{1, Q} \\
d W_{t}^{2, Q} \\
d W_{t}^{3, Q}
\end{array}\right) .
\end{aligned}
$$

\footnotetext{
${ }^{10}$ Note that, we again fix $\varepsilon=10^{-6}$ to approximate the unit-root property imposed in the $\mathrm{AFNS}_{0}$ model.
} 
In this model class, the factor loadings in the zero-coupon bond price function are given by the unique solution to

$$
\begin{aligned}
& \frac{d B^{1}(t, T)}{d t}=1+\varepsilon B^{1}(t, T)-\frac{1}{2} \sigma_{11}^{2} B^{1}(t, T)^{2} \\
& \frac{d B^{2}(t, T)}{d t}=1+\lambda B^{2}(t, T)-\frac{1}{2} \sigma_{22}^{2} B^{2}(t, T)^{2} \\
& \frac{d B^{3}(t, T)}{d t}=-\lambda B^{2}(t, T)+\lambda B^{3}(t, T)-\frac{1}{2} \sigma_{33}^{2} B^{3}(t, T)^{2}
\end{aligned}
$$

while the $A(t, T)$-function in the yield-adjustment term is given by the solution to:

$$
\frac{d A(t, T)}{d t}=-B(t, T)^{\prime} K^{Q} \theta^{Q}
$$

Applying the extended affine risk premium specification, the maximally flexible affine $P$-dynamics are given by

$$
\begin{aligned}
\left(\begin{array}{c}
d X_{t}^{1} \\
d X_{t}^{2} \\
d X_{t}^{3}
\end{array}\right) & =\left(\begin{array}{ccc}
\kappa_{11}^{P} & \kappa_{12}^{P} & \kappa_{13}^{P} \\
\kappa_{21}^{P} & \kappa_{22}^{P} & \kappa_{23}^{P} \\
\kappa_{31}^{P} & \kappa_{32}^{P} & \kappa_{33}^{P}
\end{array}\right)\left[\left(\begin{array}{c}
\theta_{1}^{P} \\
\theta_{2}^{P} \\
\theta_{3}^{P}
\end{array}\right)-\left(\begin{array}{c}
X_{t}^{1} \\
X_{t}^{2} \\
X_{t}^{3}
\end{array}\right)\right] d t \\
& +\left(\begin{array}{ccc}
\sigma_{11} & 0 & 0 \\
0 & \sigma_{22} & 0 \\
0 & 0 & \sigma_{33}
\end{array}\right)\left(\begin{array}{ccc}
\sqrt{X_{t}^{1}} & 0 & 0 \\
0 & \sqrt{X_{t}^{2}} & 0 \\
0 & 0 & \sqrt{X_{t}^{3}}
\end{array}\right)\left(\begin{array}{c}
d W_{t}^{1, P} \\
d W_{t}^{2, P} \\
d W_{t}^{3, P}
\end{array}\right) .
\end{aligned}
$$

To keep this model class arbitrage-free, all three state variables must be prevented from hitting the zero-boundary. We ensure this by imposing the Feller condition on their parameters under both probability measures, i.e.,

$$
\begin{array}{lll}
\kappa_{11}^{P} \theta_{1}^{P}+\kappa_{12}^{P} \theta_{2}^{P}+\kappa_{13}^{P} \theta_{3}^{P}>\frac{1}{2} \sigma_{11}^{2} & \text { and } \quad & \varepsilon \theta_{1}^{Q}>\frac{1}{2} \sigma_{11}^{2}, \\
\kappa_{21}^{P} \theta_{1}^{P}+\kappa_{22}^{P} \theta_{2}^{P}+\kappa_{23}^{P} \theta_{3}^{P}>\frac{1}{2} \sigma_{22}^{2} & \text { and } \quad & \lambda \theta_{2}^{Q}-\lambda \theta_{3}^{Q}>\frac{1}{2} \sigma_{22}^{2}, \\
\kappa_{31}^{P} \theta_{1}^{P}+\kappa_{32}^{P} \theta_{2}^{P}+\kappa_{33}^{P} \theta_{3}^{P}>\frac{1}{2} \sigma_{33}^{2} & \text { and } \quad \lambda \theta_{3}^{Q}>\frac{1}{2} \sigma_{33}^{2} .
\end{array}
$$

Furthermore, to have well-defined processes for $X_{t}^{1}, X_{t}^{2}$, and $X_{t}^{3}$, the sign of the effect that the factors have on each other must be positive, which we impose with the restrictions $\kappa_{12}^{P} \leq 0$, $\kappa_{13}^{P} \leq 0, \kappa_{21}^{P} \leq 0, \kappa_{23}^{P} \leq 0, \kappa_{31}^{P} \leq 0$, and $\kappa_{32}^{P} \leq 0$. Note that these restrictions imply that the three square-root processes cannot be negatively correlated. In total, there are 19 parameters in the maximally flexible specification of this class of models. 


\subsection{Estimation Methodology}

We estimate the stochastic volatility models using the Kalman filter. The zero-coupon yields are affine functions of the state variables,

$$
y_{t}(\tau)=-\frac{1}{\tau} B(\tau)^{\prime} X_{t}-\frac{1}{\tau} A(\tau)+\varepsilon_{t}(\tau)
$$

where $\varepsilon_{t}(\tau)$ represent i.i.d. Gaussian white noise measurement errors. The conditional mean for multi-dimensional affine diffusion processes is given by

$$
E^{P}\left[X_{T} \mid X_{t}\right]=\left(I-\exp \left(-K^{P}(T-t)\right)\right) \theta^{P}+\exp \left(-K^{P}(T-t)\right) X_{t},
$$

where $\exp \left(-K^{P}(T-t)\right)$ is a matrix exponential. In general, the conditional covariance matrix for affine diffusion processes is given by

$$
V^{P}\left[X_{T} \mid X_{t}\right]=\int_{t}^{T} \exp \left(-K^{P}(T-s)\right) \Sigma D\left(E^{P}\left[X_{s} \mid X_{t}\right]\right) D\left(E^{P}\left[X_{s} \mid X_{t}\right]\right)^{\prime} \Sigma^{\prime} \exp \left(-\left(K^{P}\right)^{\prime}(T-s)\right) d s .
$$

Stationarity of the system under the $P$-measure is ensured if the real components of all the eigenvalues of $K^{P}$ are positive, and this condition is imposed in all estimations. For this reason, we can start the Kalman filter at the unconditional mean and covariance matrix ${ }^{11}$

$$
\widehat{X}_{0}=\theta^{P} \quad \text { and } \quad \widehat{\Sigma}_{0}=\int_{0}^{\infty} e^{-K^{P} s} \Sigma D\left(\theta^{P}\right) D\left(\theta^{P}\right)^{\prime} \Sigma^{\prime} e^{-\left(K^{P}\right)^{\prime} s} d s
$$

However, the introduction of stochastic volatility implies that the factors are no longer simply Gaussian. We choose to approximate the true probability distribution of the state variables using the first and second moments and use the Kalman filter algorithm as if the state variables were Gaussian. ${ }^{12}$ The state equation is given by

$$
X_{t}=\left(I-\exp \left(-K^{P} \Delta t\right)\right) \theta^{P}+\exp \left(-K^{P} \Delta t\right) X_{t-1}+\eta_{t}, \quad \eta_{t} \sim N\left(0, V_{t-1}\right)
$$

where $\Delta t$ is the time between observations and $V_{t-1}$ is the conditional covariance matrix given in Equation (5). Furthermore, the approximation can cause the square-root processes to become negative despite the fact that the parameter sets are forced to satisfy Feller conditions

\footnotetext{
${ }^{11}$ In the estimation, we calculate the conditional and unconditional covariance matrices using the analytical solutions provided in Fisher and Gilles (1996).

${ }^{12} \mathrm{~A}$ few notable examples of papers that follow this approach include Duffee (1999), Driessen (2005), and Feldhütter and Lando (2008). Jacobs and Karoui (2009) show that use of the extended Kalman filter, which allows all yields to be measured with error, does not change their qualitative results. In contrast, CollinDufresne et al. (2009) use Bayesian estimation methods for their stochastic volatility models.
} 
and other non-negativity restrictions. Whenever this happens, we follow the literature and simply truncate those processes at zero; see Duffee (1999) for example.

In the Kalman filter estimations, the error structure is given by

$$
\left(\begin{array}{c}
\eta_{t} \\
\varepsilon_{t}
\end{array}\right) \sim N\left[\left(\begin{array}{l}
0 \\
0
\end{array}\right),\left(\begin{array}{cc}
V_{t-1} & 0 \\
0 & H
\end{array}\right)\right]
$$

where $H$ is assumed to be a diagonal matrix of the measurement error standard deviations, $\sigma_{\varepsilon}\left(\tau_{i}\right)$, that are specific to each yield maturity in the data set. The linear least-squares optimality of the Kalman filter requires that the white noise transition and measurement errors be orthogonal to the initial state; i.e., $E\left[f_{0} \eta_{t}^{\prime}\right]=0$ and $E\left[f_{0} \varepsilon_{t}^{\prime}\right]=0$. Finally, the standard deviations of the estimated parameters are calculated as

$$
\Sigma(\widehat{\psi})=\frac{1}{T}\left[\frac{1}{T} \sum_{t=1}^{T} \frac{\partial \log l_{t}(\widehat{\psi})}{\partial \psi} \frac{\partial \log l_{t}(\widehat{\psi})^{\prime}}{\partial \psi}\right]^{-1}
$$

where $\widehat{\psi}$ denotes the optimal parameter set.

\subsection{Model-Implied Conditional Yield Volatility}

Throughout the paper, the model-implied predicted one-month conditional yield volatility measures we refer to are given by the square root of

$$
V_{t}^{P}\left[y_{T}(\tau)\right]=\frac{1}{\tau^{2}} B(\tau)^{\prime} V_{t}^{P}\left[X_{T}\right] B(\tau)
$$

where $V_{t}^{P}\left[X_{T}\right]$ is the conditional covariance matrix of the state variables provided in Equation (5), $T-t=\frac{1}{12}$, and $\tau$ is the yield maturity in years.

\section{Model Estimates from Daily U.S. Treasury Yields}

We estimate our AFNS models with stochastic volatility using U.S. Treasury zero-coupon bond yields from the Gürkaynak et al. (2007, henceforth GSW) database. ${ }^{13}$ The following eight maturities are included: 3, 6, 12, 24, 36, 60, 84, and 120 months. We use daily data and limit our sample to the period from January 2, 1985, to June 30, 2011. Researchers have typically found that three factors are sufficient to model the time-variation in the cross section of U.S. Treasury bond yields (e.g., Litterman and Scheinkman, 1991). Indeed, for

\footnotetext{
${ }^{13}$ These data are available at http://www.federalreserve.gov/econresdata/researchdata/feds200628_1.html
} 
our daily U.S. Treasury bond yield data, $99.98 \%$ of the total variation is accounted for by the first three principal components, which have level, slope, and curvature loadings across maturities. Such a pattern motivates an AFNS model with its level, slope, and curvature factor structure. Our estimated AFNS state variables are close to but not identical to the principal components.

We first examine in-sample estimation results for the most parsimonious specification with diagonal $K^{P}$ and $\Sigma$ matrices for each AFNS model class. For example, the $\mathrm{AFNS}_{1}$-L model has $P$-dynamics given by

$$
\begin{aligned}
\left(\begin{array}{c}
d X_{t}^{1} \\
d X_{t}^{2} \\
d X_{t}^{3}
\end{array}\right) & =\left(\begin{array}{ccc}
\kappa_{11}^{P} & 0 & 0 \\
0 & \kappa_{22}^{P} & 0 \\
0 & 0 & \kappa_{33}^{P}
\end{array}\right)\left[\left(\begin{array}{c}
\theta_{1}^{P} \\
\theta_{2}^{P} \\
\theta_{3}^{P}
\end{array}\right)-\left(\begin{array}{c}
X_{t}^{1} \\
X_{t}^{2} \\
X_{t}^{3}
\end{array}\right)\right] d t \\
& +\left(\begin{array}{ccc}
\sigma_{11} & 0 & 0 \\
0 & \sigma_{22} & 0 \\
0 & 0 & \sigma_{33}
\end{array}\right)\left(\begin{array}{ccc}
\sqrt{X_{t}^{1}} & 0 & 0 \\
0 & \sqrt{1+\beta_{21} X_{t}^{1}} & 0 \\
0 & 0 & \sqrt{1+\beta_{31} X_{t}^{1}}
\end{array}\right)\left(\begin{array}{c}
d W_{t}^{1, P} \\
d W_{t}^{2, P} \\
d W_{t}^{3, P}
\end{array}\right) .
\end{aligned}
$$

It suffices to only look at the parsimonious specification because the models in each $\mathrm{AFNS}_{i}$ class deliver essentially identical decompositions of the data into level, slope, and curvature factors independent of the specification of the $P$-dynamics. ${ }^{14}$ Since it is this factor decomposition that determines the shape and form of the model-implied stochastic volatility, at least at the short one-month horizon we focus on in this paper, this restriction comes at a minimal loss of generality. Furthermore, it makes the results readily comparable across model classes.

Tables 1 and 2 present our parameter estimates of the four models. ${ }^{15}$ The parameter estimates exhibit similarities across the model specifications, especially for the $K^{P}$ matrix. ${ }^{16}$ The estimated $K^{P}$ parameter for the level factor indicates the most persistence, while the curvature factor is the least persistent, in all specifications. As for both the mean parameters in $\theta^{P}$ and the $\sigma$ volatility parameters, we see some notable differences across the various models depending on whether the factor in question is generating stochastic volatility or not. For the $\theta^{P}$ parameters, the variation in the estimated values is tied to differences in the scale

\footnotetext{
${ }^{14}$ The inclusion of stochastic volatility into the AFNS model prevents us from obtaining the exact NelsonSiegel factor loadings unlike what is the case for the $\mathrm{AFNS}_{0}$ model class. Importantly, though, the NS factor loading structure is approximately preserved in all the new model classes, as desired by construction, independent of the differences in the models' ability to generate stochastic volatility.

${ }^{15}$ The fact that the $\theta^{Q}$ parameters are not statistically identifiable and fixed at zero in the Gaussian $\mathrm{AFNS}_{0}$ model is a warning that the $\theta^{Q}$ parameters in the AFNS models with stochastic volatility are likely to warrant careful treatment. For the $\mathrm{AFNS}_{2}$-LC model these issues lead us to fix $\theta_{2}^{Q}$ at a low value of 0.08 . Unreported results show that this comes at a minimum loss of generality.

${ }^{16}$ Our conclusions on volatility are likely not affected by the finite-sample bias discussed in Bauer, Rudebusch, and $\mathrm{Wu}(2012)$ due to the short one-month horizon for our volatility measures.
} 


\begin{tabular}{|c|c|c|c|c|}
\hline Parameter & $\mathrm{AFNS}_{0}$ & $\mathrm{AFNS}_{1}-\mathrm{L}$ & $\mathrm{AFNS}_{2}-\mathrm{SC}$ & $\mathrm{AFNS}_{3}$ \\
\hline \multirow[t]{2}{*}{$\kappa_{11}^{P}$} & 0.0237 & 0.1604 & 0.0101 & 0.0313 \\
\hline & $(0.0441)$ & $(0.1197)$ & $(0.0472)$ & $(0.0519)$ \\
\hline \multirow[t]{2}{*}{$\kappa_{22}^{P}$} & 0.0947 & 0.1802 & 0.1821 & 0.2269 \\
\hline & $(0.0922)$ & $(0.1416)$ & $(0.0875)$ & $(0.0373)$ \\
\hline \multirow[t]{2}{*}{$\kappa_{33}^{P}$} & 0.6257 & 0.8734 & 1.0481 & 1.2901 \\
\hline & $(0.1865)$ & $(0.2484)$ & $(0.1024)$ & $(0.0861)$ \\
\hline \multirow[t]{2}{*}{$\theta_{1}^{P}$} & 0.0872 & 0.0628 & -0.0110 & 0.0304 \\
\hline & $(0.0245)$ & $(0.0163)$ & $(0.0792)$ & $(0.0483)$ \\
\hline \multirow[t]{2}{*}{$\theta_{2}^{P}$} & -0.0390 & -0.0232 & 0.0539 & 0.0210 \\
\hline & $(0.0237)$ & $(0.0226)$ & $(0.0125)$ & $(0.0036)$ \\
\hline \multirow[t]{2}{*}{$\theta_{3}^{P}$} & -0.0184 & -0.0050 & 0.0685 & 0.0500 \\
\hline & $(0.0088)$ & $(0.0075)$ & $(0.0058)$ & (0.0028) \\
\hline \multirow[t]{2}{*}{$\sigma_{11}$} & 0.0058 & 0.0606 & 0.0051 & 0.0436 \\
\hline & $(0.0000)$ & $(0.0003)$ & $(0.0001)$ & $(0.0005)$ \\
\hline \multirow[t]{2}{*}{$\sigma_{22}$} & 0.0092 & 0.0004 & 0.0364 & 0.0312 \\
\hline & $(0.0001)$ & $(0.0000)$ & $(0.0003)$ & $(0.0004)$ \\
\hline \multirow{2}{*}{$\sigma_{33}$} & 0.0297 & 0.0313 & 0.1014 & 0.1226 \\
\hline & $(0.0002)$ & $(0.0006)$ & $(0.0007)$ & $(0.0012)$ \\
\hline \multirow[t]{2}{*}{$\beta_{11}$} & - & - & - & - \\
\hline & - & - & - & - \\
\hline \multirow[t]{2}{*}{$\beta_{12}$} & - & - & 0.0000 & - \\
\hline & - & - & $(1.2560)$ & - \\
\hline \multirow[t]{2}{*}{$\beta_{13}$} & - & - & 0.0000 & - \\
\hline & - & - & $(0.5238)$ & - \\
\hline \multirow[t]{2}{*}{$\beta_{21}$} & - & 23,245 & - & - \\
\hline & - & $(7.2310)$ & - & - \\
\hline \multirow[t]{2}{*}{$\beta_{22}$} & - & - & - & - \\
\hline & - & - & - & - \\
\hline \multirow[t]{2}{*}{$\beta_{23}$} & - & - & - & - \\
\hline & - & - & - & - \\
\hline \multirow[t]{2}{*}{$\beta_{31}$} & - & 0.0000 & - & - \\
\hline & - & $(0.5657)$ & - & - \\
\hline \multirow[t]{2}{*}{$\beta_{32}$} & - & - & - & - \\
\hline & - & - & - & - \\
\hline \multirow[t]{2}{*}{$\beta_{33}$} & - & - & - & - \\
\hline & - & - & - & - \\
\hline
\end{tabular}

Table 1: Parameter Estimates of the $P$-Dynamics.

The table contains the estimated $K^{P}$ matrix, $\theta^{P}$ vector, $\Sigma$ matrix, and $\beta$ volatility sensitivity parameters for the $P$-dynamics in the $\mathrm{AFNS}_{i}$ models for U.S. Treasury yields. Estimated standard deviations for the parameter estimates are given in parentheses. The estimations are based on daily observations from January 2, 1985, to June 30, 2011.

at which each factor operates. Since the factors are latent, this level varies and depends on which factors generate stochastic volatility and therefore have to be bound away from the zero-boundary. Finally, the $\beta$ volatility sensitivity parameters suggest that the level factor plays a role in generating stochastic volatility for the slope factor, but not for the curvature factor. Furthermore, there is little evidence that slope and curvature play a role for the 


\begin{tabular}{|c|c|c|c|c|}
\hline Parameter & $\mathrm{AFNS}_{0}$ & $\mathrm{AFNS}_{1}-\mathrm{L}$ & $\mathrm{AFNS}_{2}-\mathrm{SC}$ & $\mathrm{AFNS}_{3}$ \\
\hline$\theta_{1}^{Q}$ & - & 3,105 & - & 990.1 \\
& - & $(18.95)$ & - & $(16.18)$ \\
$\theta_{2}^{Q}$ & - & - & 0.08 & 0.0553 \\
& - & - & - & $(0.0001)$ \\
$\theta_{3}^{Q}$ & - & - & 0.0787 & 0.0537 \\
& - & - & $(0.0002)$ & $(0.0002)$ \\
\hline$\lambda$ & 0.4667 & 0.5964 & 0.5203 & 0.3072 \\
& $(0.0011)$ & $(0.0009)$ & $(0.0013)$ & $(0.0008)$ \\
\hline Max $\log L$ & $322,626.8$ & $332,897.1$ & $316,857.1$ & $292,381.0$ \\
\hline
\end{tabular}

Table 2: Parameter Estimates of the $Q$-Dynamics.

The table contains the estimated $\theta^{Q}$ vector and $\lambda$ parameters for the $Q$-dynamics in the $\mathrm{AFNS}_{i}$ models for U.S. Treasury yields. Estimated standard deviations for the parameter estimates are given in parentheses. The estimations are based on daily observations from January 2, 1985, to June 30, 2011. The maximum log likelihood values are reported, although the models are non-nested.

volatility of the level factor in this sample of U.S. Treasury yields.

If we turn to a performance comparison of the various $\mathrm{AFNS}_{i}$ specifications, we can start by comparing the obtained maximum log likelihood values reported in Table 2. Even though all $\mathrm{AFNS}_{i}$ models are non-nested and therefore not directly comparable, the relatively large differences in likelihood values still suggest that the $\mathrm{AFNS}_{1}$-L model provides the overall best fit to the cross-sectional and time-series variation of the data. On the other hand, the $\mathrm{AFNS}_{3}$ model obtains a markedly lower maximum likelihood value than any of the other models. This model is restricted by the fact that all three factors have to remain non-negative, and one or more of these restrictions are binding periodically, not least during the last three years of the sample with the low interest rate environment in the wake of the financial crisis of 2007 and 2008. Duffee (2002), in his analysis of general affine $A_{i}(3)$ term structure models, also finds that the $A_{1}(3)$ model class performs the best, and the $A_{3}(3)$ model class the poorest. Note, though, that he only uses essentially affine risk premium specifications, which are less general than the extended affine risk premium specifications applied in this paper.

Another way to assess the performance of the different AFNS specifications of stochastic volatility is to examine the cross-sectional fit of the yield curve, as shown in Table 3 using root-mean-squared-error for the models' fitted yields. Relative to the $\mathrm{AFNS}_{0}$ specification, the introduction of stochastic volatility reduces the RMSE of the fitted yields for the shortterm three- and six-month maturities. However, for the remaining maturities, the stochastic volatility specifications do not necessarily insure a reduction in the RMSE measure with one exception, the $\mathrm{AFNS}_{1}$-L model does deliver a uniform improvement in model fit over the 


\begin{tabular}{|c|c|c|c|c|}
\hline \multirow{2}{*}{$\begin{array}{c}\text { Maturity } \\
\text { in months }\end{array}$} & \multicolumn{4}{|c|}{ RMSE for AFNS models } \\
\cline { 2 - 5 } & AFNS $_{0}$ & AFNS $_{1}-\mathrm{L}$ & $\mathrm{AFNS}_{2}$-SC & AFNS $_{3}$ \\
\hline 3 & 20.93 & 19.52 & 9.64 & 12.47 \\
6 & 9.32 & 8.40 & 0.58 & 3.64 \\
12 & 0.12 & 0.01 & 5.36 & 9.91 \\
24 & 2.37 & 1.76 & 3.73 & 12.28 \\
36 & 0.00 & 0.00 & 2.47 & 9.14 \\
60 & 2.78 & 1.58 & 3.78 & 3.15 \\
84 & 1.85 & 0.58 & 2.47 & 6.03 \\
120 & 9.68 & 5.03 & 11.32 & 11.69 \\
\hline
\end{tabular}

\section{Table 3: RMSE of Fitted Yields.}

The table presents the root-mean-squared errors for the fitted U.S. Treasury yields across the eight maturities in the $\mathrm{AFNS}_{i}$ models. The sample covers the period from January 2, 1985, to June 30, 2011. All numbers are expressed in basis points.

$\mathrm{AFNS}_{0}$ model. Furthermore, the $\mathrm{AFNS}_{2}$-SC model delivers the overall most balanced fit to the data. Finally, the $\mathrm{AFNS}_{3}$ model falls in between with a decent fit for all eight maturities. Thus, based on the evidence so far, there is no basis for either disqualifying or preferring any particular of the new $\mathrm{AFNS}_{i}$ model classes with stochastic volatility over the others or the original $\mathrm{AFNS}_{0}$ model. ${ }^{17}$ Of course, from a mechanical point of view, the $\mathrm{AFNS}_{3}$ specification has the ability to induce the greatest degree of stochastic volatility of all the specifications and thus should be best suited ex ante to closely match the observed data characteristics in terms of yield volatility in addition to providing a good in-sample fit to the cross section of yields.

\section{$5 \quad$ Yield Volatility Analysis}

Here we analyze the ability of the AFNS models with stochastic volatility to predict conditional realized yield volatility at a high frequency. The results favor the $\mathrm{AFNS}_{3}$ model, which has stochastic yield volatility generated through all three spanned factors. Thus, we test the ability of this model to match the unconditional first and second moments of our realized yield volatility series, where the results again are generally favorable.

\subsection{Conditional Yield Volatility Results}

Collin-Dufresne et al. (2009) argue that there is a potential tension in affine models between fitting the cross section of yields and capturing their stochastic volatility. They further

\footnotetext{
${ }^{17}$ Bikbov and Chernov (2011) report similar findings in their analysis of LIBOR and eurodollar futures rates using three-factor affine term structure models with and without stochastic volatility.
} 


\begin{tabular}{|c|c|c|c|c|}
\hline \multirow{2}{*}{ Correlation } & \multicolumn{4}{|c|}{ Three-month U.S. Treasury yield } \\
\hline & $\mathrm{AFNS}_{0}$ & $\mathrm{AFNS}_{1}-\mathrm{L}$ & $\mathrm{AFNS}_{2}-\mathrm{SC}$ & $\mathrm{AFNS}_{3}$ \\
\hline \multirow{4}{*}{$\begin{array}{l}\mathrm{AFNS}_{0} \\
\mathrm{AFNS}_{1}-\mathrm{L} \\
\mathrm{AFNS}_{2} \text {-SC } \\
\mathrm{AFNS}_{3} \\
\end{array}$} & \multirow[t]{4}{*}{1} & 0 & 0 & 0 \\
\hline & & 1 & -0.093 & 0.743 \\
\hline & & & 1 & 0.543 \\
\hline & & & & 1 \\
\hline \multirow{2}{*}{ Correlation } & \multicolumn{4}{|c|}{ Two-year U.S. Treasury yield } \\
\hline & $\mathrm{AFNS}_{0}$ & $\mathrm{AFNS}_{1}-\mathrm{L}$ & $\mathrm{AFNS}_{2}-\mathrm{SC}$ & $\mathrm{AFNS}_{3}$ \\
\hline \multirow{4}{*}{$\begin{array}{l}\mathrm{AFNS}_{0} \\
\mathrm{AFNS}_{1}-\mathrm{L} \\
\mathrm{AFNS}_{2} \text {-SC } \\
\mathrm{AFNS}_{3} \\
\end{array}$} & \multirow[t]{4}{*}{1} & 0 & 0 & 0 \\
\hline & & 1 & 0.258 & 0.906 \\
\hline & & & 1 & 0.621 \\
\hline & & & & 1 \\
\hline \multirow{2}{*}{ Correlation } & \multicolumn{4}{|c|}{ Five-year U.S. Treasury yield } \\
\hline & $\mathrm{AFNS}_{0}$ & $\mathrm{AFNS}_{1}-\mathrm{L}$ & $\mathrm{AFNS}_{2}-\mathrm{SC}$ & $\mathrm{AFNS}_{3}$ \\
\hline \multirow{4}{*}{$\begin{array}{l}\mathrm{AFNS}_{0} \\
\mathrm{AFNS}_{1} \text {-L } \\
\mathrm{AFNS}_{2} \text {-SC } \\
\mathrm{AFNS}_{3} \\
\end{array}$} & & 0 & 0 & 0 \\
\hline & & 1 & 0.374 & 0.918 \\
\hline & & & 1 & 0.658 \\
\hline & & & & 1 \\
\hline \multirow{2}{*}{ Correlation } & \multicolumn{4}{|c|}{ Ten-year U.S. Treasury yield } \\
\hline & $\mathrm{AFNS}_{0}$ & $\mathrm{AFNS}_{1}-\mathrm{L}$ & $\mathrm{AFNS}_{2}-\mathrm{SC}$ & $\mathrm{AFNS}_{3}$ \\
\hline $\mathrm{AFNS}_{0}$ & 1 & 0 & 0 & 0 \\
\hline $\mathrm{AFNS}_{1}$-L & & 1 & 0.394 & 0.947 \\
\hline $\mathrm{AFNS}_{2}$-SC & & & 1 & 0.605 \\
\hline $\mathrm{AFNS}_{3}$ & & & & 1 \\
\hline
\end{tabular}

Table 4: Pairwise Correlations of the One-Month Conditional Standard Deviation of Four U.S. Treasury Yields across the AFNS $_{i}$ Models.

The table contains the pairwise correlations between the one-month conditional standard deviations of the three-month, the two-year, the five-year, and the ten-year U.S. Treasury yields predicted by the $\mathrm{AFNS}_{i}$ models. The estimations are based on daily data from January 2, 1985, to June 30, 2011.

demonstrate that to allow only one factor to generate stochastic volatility in a three-factor affine model appears to be too restrictive to fit both aspects of the data. By allowing for more factors to generate stochastic volatility in our AFNS specifications, we hope to mitigate this potential tension. The AFNS specifications with stochastic volatility do not differ markedly in terms of fitting the observed U.S. Treasury yield curve. However, predicted volatility measures of these specifications do differ. Table 4 reports a large dispersion in the pairwise correlations of the predicted conditional yield volatility series for four maturities across all four $\mathrm{AFNS}_{i}$ models.

To evaluate the fit of these predicted one-month-ahead conditional yield standard deviations, we compare them to a standard measure of realized volatility based on the daily data used in the model estimations. We generate the realized standard deviation of daily changes in interest rates for the 31-day period ahead on a rolling basis. The realized variance measure is used by Andersen and Benzoni (2010), Collin-Dufresne et al. (2009), as well as Jacobs 
and Karoui (2009) in their assessments of stochastic volatility models. This measure is fully nonparametric and has been shown to converge to the underlying realization of the conditional variance as the sampling frequency increases; see Andersen et al. (2003) for details. The square root of this measure retains these properties. For each observation date $t$ we determine the number of trading days $N$ during the subsequent 31-day time window (where $\mathrm{N}$ is most often 21 or 22$).{ }^{18}$ We then generate the realized standard deviation as

$$
R V_{t, \tau}^{S T D}=\sqrt{\sum_{n=1}^{N} \Delta y_{t+n / N}^{2}(\tau)}
$$

where $\Delta y_{t+n / N}(\tau)$ is the change in yield $y(\tau)$ from trading day $(n-1)$ to trading day $n .{ }^{19}$

Figure 1 plots the realized 31-day ahead volatility series over the full sample period for four maturities: 3 months, 2 years, 5 years, and 10 years. In each chart, we include the corresponding predicted yield volatility from our four AFNS models. The figure highlights three empirical features of the realized volatilities. First, the realized volatility series become less volatile as the maturity increases. Table 5 shows that the standard deviation of the realized standard deviation for the changes in the three-month yield is almost 1.5 times greater than that of the ten-year yield. ${ }^{20}$ This pattern of declining variation as maturity increases suggests that the standard deviations generated by all the model specifications should exhibit better fit as maturity increases, which is, in general, the pattern observed in Table 6, which contains the summary statistics of the errors between the model-implied onemonth conditional standard deviations and the 31-day-ahead realized volatility for all eight maturities in the U.S. Treasury data.

Second, note that the $\mathrm{AFNS}_{0}$ and $\mathrm{AFNS}_{2}$-SC models produce consistently low RMSE values between predicted and realized standard deviations for all maturities. However, the degree of variation exhibited by these predicted standard deviations is quite low relative to the $\mathrm{AFNS}_{3}$ specification. As our objective is to best capture the stochastic volatility of these interest rate series, the $\mathrm{AFNS}_{3}$ specification stands out as a model that delivers a reasonable fit to both the cross section of yields and the cross section of realized yield volatilities.

Third, aside from measures of fit, the correlations between the predicted and realized

\footnotetext{
${ }^{18}$ As a consequence, the realized volatility measure can be calculated for the period from January 2, 1985 to May 27, 2011.

${ }^{19}$ Note that other measures of realized volatility have been used in the literature, such as the realized mean absolute deviation measure as well as fitted GARCH estimates. Collin-Dufresne et al. (2009) also use option-implied volatility as a measure of realized volatility.

${ }^{20}$ This pattern is similar to the one presented by Jacobs and Karoui (2009) for monthly Treasury yields, although their measures decline at a slower rate as maturity increases. The differences may be due to the longer sample period from 1970 to 2003 that they use.
} 


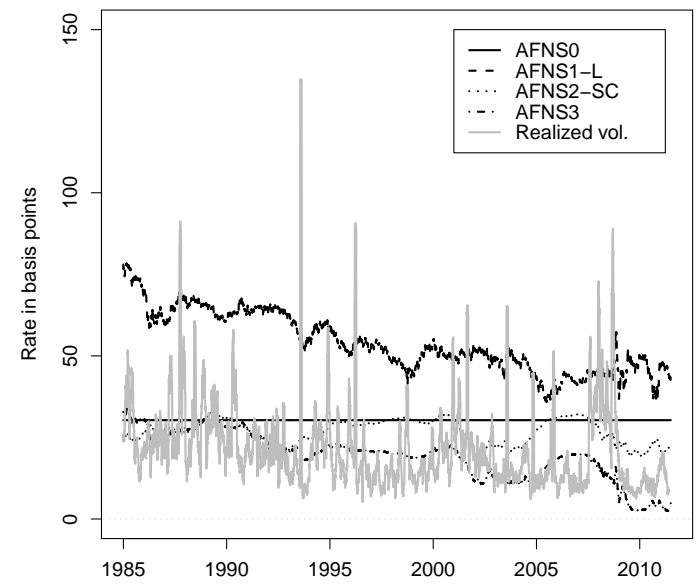

(a) Three-month Treasury yield.

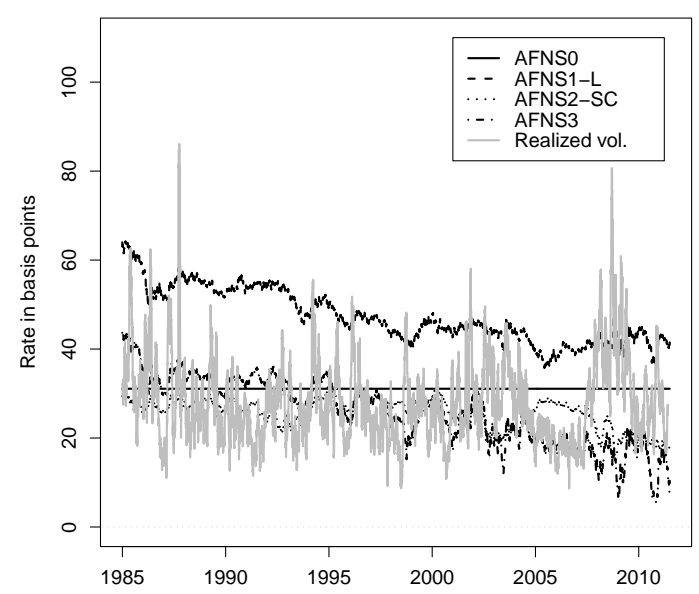

(c) Five-year Treasury yield.

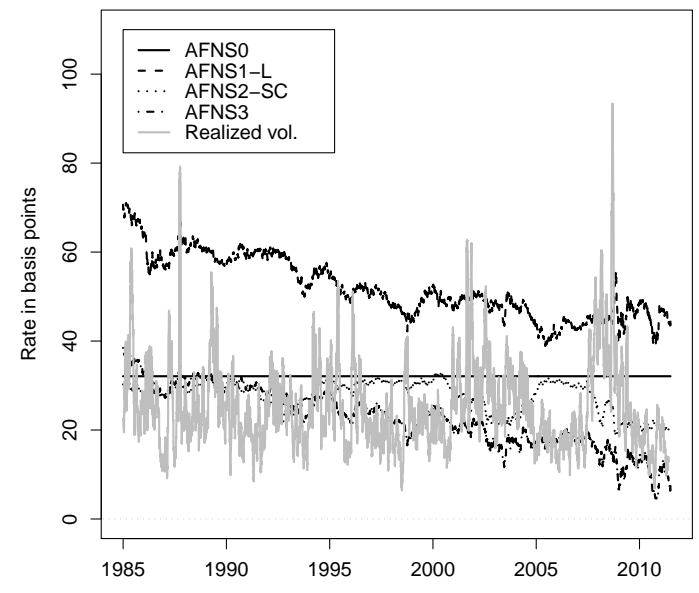

(b) Two-year Treasury yield.

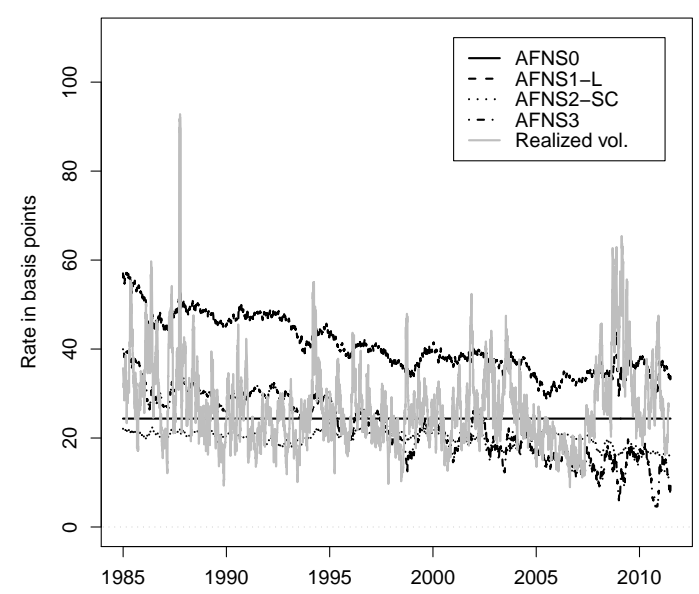

(d) Ten-year Treasury yield.

Figure 1: Predicted and Realized One-Month Conditional Standard Deviations of U.S. Treasury Yields.

standard deviations have been used as measures of how well a model is able to capture the stochastic volatility observed in the data. The top panel of Table 7 presents the correlations across the model specifications and maturities that we examine over the full sample period. The correlations are relatively low, reaching a maximum of just 0.31 , and often being negative with the lowest value being -0.24 . While these low values could be interpreted to imply that the $\mathrm{AFNS}_{i}$ model specifications are not capable of capturing the stochastic volatility in the data very well, the subsample correlation results reported by Jacobs and Karoui (2009) suggest 


\begin{tabular}{|c|c|c|c|}
\hline $\begin{array}{c}\text { Maturity } \\
\text { in months }\end{array}$ & $\begin{array}{c}\text { Mean } \\
\text { in bps }\end{array}$ & $\begin{array}{c}\text { Std. dev. } \\
\text { in bps }\end{array}$ & $\begin{array}{c}\text { Std. dev. } \\
\text { ratio }\end{array}$ \\
\hline 3 & 22.05 & 14.26 & 1.48 \\
6 & 18.61 & 11.57 & 1.20 \\
12 & 20.90 & 10.49 & 1.09 \\
24 & 25.58 & 10.21 & 1.06 \\
36 & 27.60 & 10.13 & 1.05 \\
60 & 28.39 & 9.94 & 1.03 \\
84 & 28.03 & 9.81 & 1.02 \\
120 & 27.36 & 9.61 & 1.00 \\
\hline
\end{tabular}

Table 5: Summary Statistics for the 31-Day Realized Standard Deviations of U.S. Treasury Yields.

The summary statistics are for the 31-day rolling realized standard deviations based on the daily U.S. Treasury data from January 2, 1985, to June 30, 2011. The standard deviation ratio is calculated as the standard deviation in question divided by the standard deviation for the ten-year maturity.

\begin{tabular}{|c|c|c||c|c||c|c||c|c|}
\hline \multicolumn{9}{|c|}{ RMSE for predicted conditional yield standard deviations } \\
\hline \hline \multirow{2}{*}{$\begin{array}{c}\text { Maturity } \\
\text { in months }\end{array}$} & \multicolumn{2}{|c|}{ AFNS $_{0}$} & \multicolumn{2}{c|}{ AFNS ${ }_{1}$-L } & \multicolumn{2}{|c|}{ AFNS ${ }_{2}$-SC } & \multicolumn{2}{c|}{ AFNS $_{3}$} \\
\cline { 2 - 8 } & Mean & RMSE & Mean & RMSE & Mean & RMSE & Mean & RMSE \\
\hline 3 & 8.24 & 16.47 & 31.84 & 35.07 & 4.75 & 15.25 & -2.60 & 14.30 \\
6 & 11.40 & 16.24 & 34.44 & 36.59 & 7.90 & 14.23 & 1.01 & 11.55 \\
12 & 9.55 & 14.18 & 31.50 & 33.63 & 5.90 & 12.41 & -0.39 & 11.20 \\
24 & 6.51 & 12.11 & 26.34 & 28.76 & 2.26 & 11.39 & -2.71 & 12.18 \\
36 & 5.10 & 11.34 & 23.19 & 25.81 & 0.26 & 11.38 & -2.91 & 12.63 \\
60 & 2.68 & 10.30 & 18.94 & 21.93 & -2.68 & 11.48 & -2.40 & 12.74 \\
84 & 0.14 & 9.81 & 16.11 & 19.44 & -5.02 & 11.82 & -2.80 & 12.59 \\
120 & -2.99 & 10.07 & 13.32 & 16.98 & -7.38 & 12.51 & -4.63 & 12.49 \\
\hline
\end{tabular}

Table 6: Summary Statistics for the Prediction Errors of the One-Month Conditional Yield Standard Deviations.

The table presents the mean and root mean squared error of the model-implied one-month conditional bond yield standard deviations relative to the 31-day realized standard deviations based on the daily U.S. Treasury data over the period from January 2, 1985, to June 30, 2011. All numbers are measured in basis points.

that sample periods could play a key, but as of yet not well understood, role in this analysis. For their monthly and weekly U.S. Treasury yields, they find that term structure models do not generate stochastic volatility measures that match the data well for the post-1991 period. ${ }^{21}$ For this reason we split our sample into three periods. The first period covers the seven-year period from January 2, 1985 to December 31, 1991. The second period covers the eleven years from January 2, 1992 to December 31, 2002. Finally, the third period covers the eight years from January 2, 2003 to May 27, 2011, which is the last day for which we can calculate the 31-day ahead realized volatility measure.

\footnotetext{
${ }^{21}$ Please note that our correlation values are not directly comparable to the correlations reported by Jacobs and Karoui (2009) as they smooth their logged realized variance series using an ARMA(1,1) filter.
} 


\begin{tabular}{|c|c|c|c|}
\hline \multirow{2}{*}{$\begin{array}{l}\text { Maturity } \\
\text { in months }\end{array}$} & \multicolumn{3}{|c|}{ Jan. 2, 1985 to May 27, 2011} \\
\hline & $\mathrm{AFNS}_{1}-\mathrm{L}$ & $\mathrm{AFNS}_{2}-\mathrm{SC}$ & $\mathrm{AFNS}_{3}$ \\
\hline 3 & 0.267 & 0.068 & 0.279 \\
\hline 6 & 0.279 & 0.074 & 0.308 \\
\hline 12 & 0.201 & 0.026 & 0.207 \\
\hline 24 & 0.127 & -0.106 & 0.063 \\
\hline 36 & 0.111 & -0.180 & 0.014 \\
\hline 60 & 0.112 & -0.239 & -0.007 \\
\hline 84 & 0.126 & -0.240 & 0.010 \\
\hline 120 & 0.156 & -0.212 & 0.056 \\
\hline Maturity & \multicolumn{3}{|c|}{ Jan. 2, 1985 to Dec. 31,1991} \\
\hline in months & $\mathrm{AFNS}_{1}-\mathrm{L}$ & $\mathrm{AFNS}_{2}-\mathrm{SC}$ & $\mathrm{AFNS}_{3}$ \\
\hline 3 & 0.175 & 0.073 & 0.179 \\
\hline 6 & 0.226 & 0.026 & 0.212 \\
\hline 12 & 0.226 & 0.152 & 0.286 \\
\hline 24 & 0.246 & 0.301 & 0.308 \\
\hline 36 & 0.263 & 0.326 & 0.307 \\
\hline 60 & 0.260 & 0.329 & 0.311 \\
\hline 84 & 0.250 & 0.322 & 0.309 \\
\hline 120 & 0.244 & 0.308 & 0.300 \\
\hline \multirow{2}{*}{$\begin{array}{l}\text { Maturity } \\
\text { in months }\end{array}$} & \multicolumn{3}{|c|}{ Jan. 2, 1992 to Dec. 31, 2002} \\
\hline & $\mathrm{AFNS}_{1}-\mathrm{L}$ & $\mathrm{AFNS}_{2}-\mathrm{SC}$ & $\mathrm{AFNS}_{3}$ \\
\hline 3 & 0.074 & -0.062 & 0.048 \\
\hline 6 & 0.130 & -0.162 & 0.041 \\
\hline 12 & 0.085 & -0.293 & -0.158 \\
\hline 24 & 0.082 & -0.314 & -0.097 \\
\hline 36 & 0.099 & -0.295 & -0.033 \\
\hline 60 & 0.071 & -0.273 & -0.028 \\
\hline 84 & 0.006 & -0.232 & -0.051 \\
\hline 120 & -0.074 & -0.154 & -0.077 \\
\hline \multirow{2}{*}{$\begin{array}{l}\text { Maturity } \\
\text { in months }\end{array}$} & \multicolumn{3}{|c|}{ Jan. 2, 2003 to May 27, 2011} \\
\hline & $\mathrm{AFNS}_{1-\mathrm{L}}$ & $\mathrm{AFNS}_{2}-\mathrm{SC}$ & $\mathrm{AFNS}_{3}$ \\
\hline 3 & 0.122 & 0.099 & 0.223 \\
\hline 6 & 0.046 & 0.179 & 0.286 \\
\hline 12 & 0.137 & 0.093 & 0.274 \\
\hline 24 & 0.289 & -0.165 & 0.055 \\
\hline 36 & 0.346 & -0.334 & -0.097 \\
\hline 60 & 0.365 & -0.514 & -0.219 \\
\hline 84 & 0.350 & -0.584 & -0.241 \\
\hline 120 & 0.325 & -0.618 & -0.215 \\
\hline
\end{tabular}

Table 7: Correlations Between Predicted and Realized Yield Standard Deviations. The table presents the correlations between the 31-day predicted and realized standard deviations for U.S. Treasury yields. The top panel is based on the full sample from January 2, 1985 to May 27, 2011 (6,583 daily observations). The second panel is based on the period from January 2, 1985 to December 31, 1991 (1,747 daily observations). The third panel is based on the period from January 2, 1992 to December 31, 2002 (2,731 daily observations). The bottom panel is based on the period January 2, 2003 to May 27, 2011 (2,105 daily observations).

Our subsample results are similar to those of Jacobs and Karoui (2009). The second panel 
of Table 7 shows these correlations for the seven years from January 2, 1985 to December 31, 1991. Clearly, these correlations are all positive, but still only reaching a maximum of 0.33 . The $\mathrm{AFNS}_{2}$-SC and $\mathrm{AFNS}_{3}$ specifications generate the highest correlations with the realized volatility series, but the greater degree of variation in the predicted standard deviations generated by the $\mathrm{AFNS}_{3}$ specification gives this model the edge. However, the bottom two panels of Table 7 present the low and mainly negative correlations for the subsequent two subsample periods. Note, though, that the $\mathrm{AFNS}_{1}$-L model stands out for the most recent eight-year period with positive correlations up to 0.37 for the three-year yield.

The key question left by the results above is to what extent we can expect ex ante predicted yield standard deviations derived from models like ours to line up with ex post realizations of yield volatility measures. To shed light on this important question, we focus on the $\mathrm{AFNS}_{3}$ model and use it in a simulation exercise to study the correlations between ex ante predicted and ex post realized conditional yield volatilities. ${ }^{22}$

To begin the exercise, we consider the $\mathrm{AFNS}_{3}$ model parameters estimated as of June 30, 2011 and reported in the last column of Tables 1 and 2 as the "true" parameters. In the next step, we use this model to simulate $N=1,000$ artificial data sets identical to the observed sample of U.S. Treasury yields. ${ }^{23}$ Specifically, (i) the number of observation dates and the time in between observations are identical to the original sample, (ii) the yield maturities on each observation date are identical to those in the original sample, and (iii) i.i.d. errors are added with a maturity-specific standard deviation given by the estimated values of $\sigma_{\varepsilon}(\tau)$ from the original sample. ${ }^{24}$ Third, we use the $N=1,000$ artificial data samples as input into the original Kalman filter estimation, whereby we obtain $N=1,000$ alternative model parameter sets. Fourth, for each simulated data sample, we use the estimated model output to generate the predicted 31-day conditional yield volatility series for all eight maturities and correlate them with the corresponding ex post 31-day realized yield volatility series. The summary statistics for the distribution of correlations across yield maturities is reported in the top panel of Table 8 .

We emphasize that all stochastic yield volatility in the simulated data is generated by the $\mathrm{AFNS}_{3}$ model and therefore spanned by construction. Despite this fact the median correlation across the $N=1,000$ simulated samples is surprisingly low for most maturities. Another observation is that the size of the median correlation is highly correlated with the measurement noise in the yield data reported in the second column of the top panel of Table

\footnotetext{
${ }^{22}$ We thank Mikhail Chernov for suggesting this exercise.

${ }^{23}$ See Christensen, Lopez, and Rudebusch (2013) for details of the model simulation.

${ }^{24}$ These error standard deviations are reported in the second column of the top panel of Table 8.
} 


\begin{tabular}{|c|c|c|c|c|c|c|c|}
\hline \multicolumn{8}{|c|}{ Distribution of correlation coefficients } \\
\hline \multirow{2}{*}{$\begin{array}{l}\text { Mat. in } \\
\text { months }\end{array}$} & \multicolumn{6}{|c|}{ 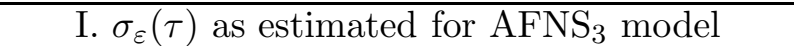 } & \multirow{2}{*}{$P(\rho \leq \widehat{\rho}(\tau))$} \\
\hline & $\overline{\sigma_{\varepsilon}(\tau)}$ & $5 \%$ & $25 \%$ & Median & $75 \%$ & $95 \%$ & \\
\hline 3 & 13.00 & -0.043 & 0.024 & 0.064 & 0.111 & 0.187 & 0.997 \\
\hline 6 & 4.31 & 0.142 & 0.241 & 0.324 & 0.415 & 0.566 & 0.445 \\
\hline 12 & 9.70 & -0.008 & 0.056 & 0.107 & 0.160 & 0.253 & 0.887 \\
\hline 24 & 12.06 & -0.020 & 0.037 & 0.080 & 0.127 & 0.196 & 0.392 \\
\hline 36 & 9.08 & 0.022 & 0.092 & 0.139 & 0.192 & 0.270 & 0.035 \\
\hline 60 & 3.79 & 0.272 & 0.340 & 0.392 & 0.457 & 0.563 & 0.000 \\
\hline 84 & 6.43 & 0.122 & 0.185 & 0.240 & 0.298 & 0.406 & 0.000 \\
\hline 120 & 11.72 & -0.015 & 0.046 & 0.090 & 0.133 & 0.203 & 0.318 \\
\hline \multirow{2}{*}{$\begin{array}{l}\text { Mat. in } \\
\text { months }\end{array}$} & \multicolumn{6}{|c|}{ II. $\sigma_{\varepsilon}(\tau)=1$ basis point for all maturities } & \multirow{2}{*}{$P(\rho \leq \widehat{\rho}(\tau))$} \\
\hline & $\overline{\sigma_{\varepsilon}(\tau)}$ & $5 \%$ & $25 \%$ & Median & $75 \%$ & $95 \%$ & \\
\hline 3 & 1.00 & 0.406 & 0.522 & 0.621 & 0.708 & 0.807 & n.a. \\
\hline 6 & 1.00 & 0.391 & 0.511 & 0.608 & 0.700 & 0.802 & n.a. \\
\hline 12 & 1.00 & 0.376 & 0.488 & 0.578 & 0.670 & 0.778 & n.a. \\
\hline 24 & 1.00 & 0.372 & 0.475 & 0.546 & 0.624 & 0.741 & n.a. \\
\hline 36 & 1.00 & 0.378 & 0.475 & 0.539 & 0.612 & 0.718 & n.a. \\
\hline 60 & 1.00 & 0.392 & 0.481 & 0.549 & 0.613 & 0.707 & n.a. \\
\hline 84 & 1.00 & 0.396 & 0.494 & 0.554 & 0.617 & 0.713 & n.a. \\
\hline 120 & 1.00 & 0.397 & 0.498 & 0.563 & 0.631 & 0.733 & n.a. \\
\hline
\end{tabular}

Table 8: Distributions of Correlations between Predicted and Realized Yield Standard Deviations From Simulated Samples of Bond Yields.

The table reports the distributions of correlations between ex ante predicted and ex post realized 31day yield standard deviation series. The data is simulated from the $\mathrm{AFNS}_{3}$ model as described in the text. The second column contains the error standard deviations (measured in basis points) used in the simulations, while the last column indicates the probability of observing the full-sample correlations between predicted and realized yield standard deviations reported for the $\mathrm{AFNS}_{3}$ model in the top panel of Table 7 .

8. The correlation is -97.2 percent. This motivates us to re-run the above exercise using a uniform low value of one basis point for all $\sigma_{\varepsilon}\left(\tau_{i}\right)$ values. ${ }^{25}$ The results are reported in the bottom panel of Table 8. Consistent with the theoretical results of Andersen et al. (2003), the predicted yield standard deviations approximate closely the realized yield volatility measures as the added white noise decline in importance. However, random microstructure noise of a size similar to the in-sample fitted errors from standard three-factor models like ours can blur this relationship significantly. To exemplify that that kind of noise likely exists in the GSW data analyzed in this paper, we note that the average absolute yield prediction errors in the construction of the data are, with few exceptions, of the order of a few basis points over

\footnotetext{
${ }^{25}$ We emphasize that we use the exact same model parameters, simulated state variables, and simulated measurement errors, $\varepsilon_{i}(\tau)$, as in the first exercise to make the results as comparable as possible. Similar results were obtained with zero measurement errors.
} 
the 1985-2007 period. Thus, this experiment shows that correlations between model-implied predictions and ex post realizations of yield volatility at high frequency may not be a reliable measure of a given model's ability to capture, or span, yield volatility unless the data quality and model fit are extremely (read: unrealistically) good.

Finally, we note that our simulation experiment is close to one undertaken by Bikbov and Chernov (2009) using an $A_{1}(3)$ model estimated on weekly data for eurodollar futures rates. However, they impose zero measurement error in their simulated data to avoid reestimating their model. Thus, unlike our experiment, their study is silent about both the role of measurement error and parameter uncertainty for the inference drawn from correlations between model-implied and realized measures of yield volatility. In terms of the latter, they use GARCH(1,1) estimated series. Still, their results are consistent with ours in that they find that correlations between the model- and $\operatorname{GARCH}(1,1)$-implied yield volatility series range from -0.44 to 0.51 even though all volatility in the simulated data is spanned by their $A_{1}(3)$ model.

To summarize, the empirical results suggest that the $\mathrm{AFNS}_{3}$ model can generate predicted volatility measures that exhibit a reasonable degree of variation and simultaneously provide a close fit to the realized volatility measures in this sample of U.S. Treasury data. Still, at a daily frequency, the correlation between the model-implied yield standard deviations and the realized yield volatility is rather low, frequently even negative. However, a simulation study reveals that this can be the case even in a situation where all structural volatility is spanned.

\subsection{Matching Unconditional Moments of Realized Yield Volatility}

To provide support for the view that affine term structure models with spanned factors only are able to capture key elements of yield level and volatility dynamics both in the time series dimension and cross-sectionally, we compare the $\mathrm{AFNS}_{3}$ model's unconditional moments of the predicted yield volatility to those of the realized yield standard deviations. ${ }^{26}$

Even though high frequency correlations between predicted and realized yield volatilities may not be informative, a good model should still be able to match the average level and variation of the realized yield volatility series. Therefore, we compare the unconditional mean and standard deviation of the model-implied one-month conditional bond yield standard

\footnotetext{
${ }^{26}$ Jagannathan, Kaplin, and Sun (2003) analyze the performance of one-, two-, and three-factor CIR models using a short sample of LIBOR and swap rates. However, they only consider completely affine risk premium specifications, which are particularly restrictive for $A_{n}(n)$ models. Still, they find that their $A_{3}(3)$ model produces small fitted errors, matches the observed yield volatility term structure, and is not rejected when they test whether the means and variances of its state variables match the corresponding model-implied theoretical distributions. The main drawback they find is its inability to price caps and swaptions, but this might be due to the restricted risk premium structure.
} 


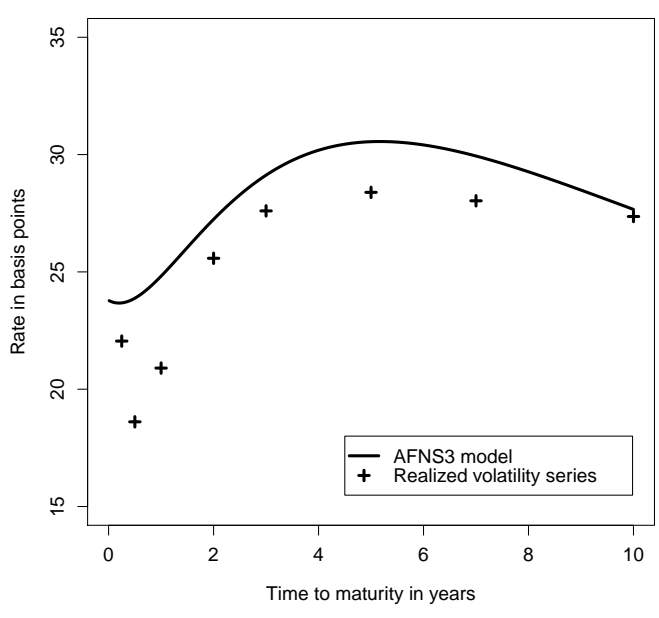

(a) Unconditional mean.

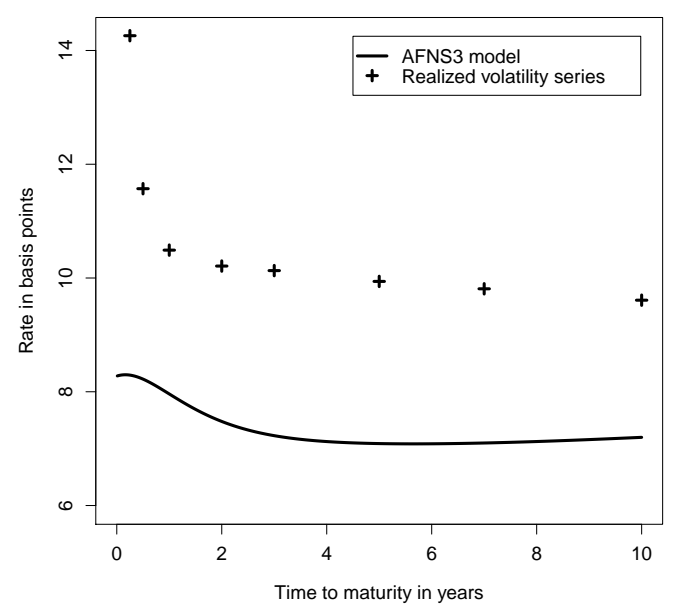

(b) Unconditional standard deviation.

Figure 2: Unconditional Mean and Standard Deviation of the One-Month Conditional Yield Standard Deviations.

Illustration of the unconditional mean and standard deviation of the one-month conditional yield volatility in the $\mathrm{AFNS}_{3}$ model. Shown are also the mean and standard deviation of the 31-day realized volatility of the eight yield maturities in the GSW Treasury data.

deviation to the mean and standard deviation of the 31-day realized yield volatilities reported in the first two columns of Table 5. The way we proceed is to simulate $N=10,000$ random draws from the unconditional distribution of $X_{t}=\left(X_{t}^{1}, X_{t}^{2}, X_{t}^{3}\right)$ in the $\mathrm{AFNS}_{3}$ model using the estimated parameters from the full sample. ${ }^{27}$ For each drawn vector of $X_{t}$, we calculate the model-implied one-month conditional yield standard deviation for all yield maturities $\tau \in(0,10)$. As all the draws are equally likely, the mean and standard deviation of the $N=$ 10,000 simulated yield standard deviations for each maturity $\tau$ represent the estimate of the unconditional mean and standard deviation, respectively, of the one-month conditional yield volatility. Figure 2 shows the model results and the sample equivalents and reveals a good fit by the $\mathrm{AFNS}_{3}$ model to these unconditional moments. ${ }^{28}$

\section{Conclusion}

In this paper, we generalize the AFNS model introduced by CDR to allow for stochastic volatility. In doing so, we introduce new specifications whose sources of stochastic volatility are different permutations of the AFNS model's three spanned factors. Our empirical exercises

\footnotetext{
${ }^{27}$ See Christensen et al. (2013) for details of the model simulation.

${ }^{28} \mathrm{We}$ have also examined whether the $\mathrm{AFNS}_{3}$ model is able to reproduce the failure of the expectations hypothesis as per Dai and Singleton (2002). We find that it is able.
} 
show that the introduction of these volatility factors does not have a significant impact on the models' fitted yield values relative to the constant volatility $\mathrm{AFNS}_{0}$ model. Furthermore, our results suggest that the $\mathrm{AFNS}_{3}$ model in particular, in which all three factors exhibit stochastic volatility, is able to generate a reasonable amount of volatility dynamics. For our daily U.S. Treasury yield data, the $\mathrm{AFNS}_{3}$ model generates the most variation in its predicted yield standard deviations and provides the closest fit to our realized yield volatility measures. None of the models generate large correlations with those realized yield volatility measures at high frequency. However, a simulation study shows that this metric is not informative about a model's ability to capture yield volatility. Furthermore, in other model validation exercises, the $\mathrm{AFNS}_{3}$ model is able to approximate the entire term structure of unconditional means and standard deviations of our realized yield volatility measures.

In conclusion, we find evidence that the modified AFNS modeling framework captures an important fraction of the stochastic volatility observed in the data in addition to preserving the good in-sample yield fit and ease of estimation that is the advantage of the original Gaussian $\mathrm{AFNS}_{0}$ model class. Still, at daily frequency, parts of the observed volatility in interest rates is only weakly associated with any of the spanned term structure factors. However, to expand the presented model framework to address these issues, is beyond the scope of this paper. Certainly, more research needs to be done to better understand whether there are any significant economic benefits to modeling the unspanned component of yield volatility, as per Collin-Dufresne and Goldstein (2002) and Collin-Dufresne et al. (2009). In a related paper, Christensen, Lopez, and Rudebusch (2012) are able to price deflation protection options embedded in Treasury inflation-protected securities (TIPS) accurately using spanned yield factors only, which suggests limited economic benefit of unspanned stochastic volatility factors. Similarly, Almeida, Graveline, and Joslin (2011), who use $A_{1}(3)$ and $A_{2}(3)$ affine models to analyze LIBOR and swap rates, find systematically large positive correlations between oneweek model-implied predicted and $\operatorname{EGARCH}(1,1)$ estimated yield volatilities. Furthermore, they show that these models are able to accurately price both interest rate swaps and volatility sensitive at-the-money caps - again suggesting that spanned risk factors may be sufficient to capture all economically relevant information. 


\section{References}

Ahn, Dong-Hyun, Robert F. Dittmar, and A. Ronald Gallant, 2002, "Quadratic Term Structure Models: Theory and Evidence," Review of Financial Studies, Vol. 15, No. 1, 243-288.

Almeida, Caio, Jeremy J. Graveline, and Scott Joslin, 2011, "Do Interest Rate Options Contain Information about Excess Returns?," Journal of Econometrics, Vol. 164, 3544.

Andersen, T., Bollerslev, T., Diebold, F.X. and Labys, P., 2003, "Modeling and Forecasting Realized Volatility," Econometrica, 71, 579-626.

Andersen, Torben G. and Luca Benzoni, 2010, "Do Bonds Span Volatility Risk in the U.S. Treasury Market? A Specification Test for Affine Term Structure Models," Journal of Finance, Vol. 65, No. 2, 603-653.

Bauer, Michael D., Glenn D. Rudebusch, and Jing (Cynthia) Wu, 2012, "Correcting Estimation Bias in Dynamic Term Structure Models," Journal of Business and Economic Statistics, Vol. 30, No. 3, 454-467.

Bikbov, Ruslan and Mikhail Chernov, 2009, "Unspanned Stochastic Volatility in Affine Models: Evidence from Eurodollar Futures and Options," Management Science, Vol. 55, No. 8, 1292-1305.

Bikbov, Ruslan and Mikhail Chernov, 2011, "Yield Curve and Volatility: Lessons from Eurodollar Futures and Options," Journal of Financial Econometrics, Vol. 9, No. 1, 66-105.

Cheridito, Patrick, Damir Filipović, and Robert L. Kimmel, 2007, "Market Price of Risk Specifications for Affine Models: Theory and Evidence," Journal of Financial Economics, Vol. 83, 123-170.

Christensen, Jens H. E., Francis X. Diebold, and Glenn D. Rudebusch, 2011, "The Affine Arbitrage-Free Class of Nelson-Siegel Term Structure Models," Journal of Econometrics, Vol. 164, 4-20.

Christensen, Jens H. E., Jose A. Lopez, and Glenn D. Rudebusch, 2010, "Inflation Expectations and Risk Premiums in an Arbitrage-Free Model of Nominal and Real Bond Yields," Journal of Money, Credit and Banking, Supplement to Vol. 42, No. 6, 143-178. 
Christensen, Jens H. E., Jose A. Lopez, and Glenn D. Rudebusch, 2012, "Pricing Deflation Risk With U.S. Treasury Yields," Working Paper 2012-07, Federal Reserve Bank of San Francisco.

Christensen, Jens H. E., Jose A. Lopez, and Glenn D. Rudebusch, 2013, "How Efficient is the Kalman Filter at Estimating Affine Term Structure Models?," Manuscript, Federal Reserve Bank of San Francisco.

Christensen, Jens H. E., Jose A. Lopez, and Glenn D. Rudebusch, 2014, "Do Central Bank Liquidity Facilities Affect Interbank Lending Rates?," Journal of Business and Economic Statistics, forthcoming.

Christensen, Jens H. E. and Glenn D. Rudebusch, 2012, "The Response of Interest Rates to U.S. and U.K. Quantitative Easing," Economic Journal, Vol. 122, F385-F414.

Collin-Dufresne, P. and Goldstein, R.S., 2002, "Do Bonds Span the Fixed Income Markets? Theory and Evidence for Unspanned Stochastic Volatility," Journal of Finance, 57, 1685-1730.

Collin-Dufresne, P., Goldstein, R.S. and Jones, C.S., 2009, "Can Interest Rate Volatility Be Extracted from the Cross-Section of Bond Yields?," Journal of Financial Economics, 94, 47-66.

Dai, Qiang and Kenneth J. Singleton, 2000, "Specification Analysis of Affine Term Structure Models," Journal of Finance, Vol. 55, 1943-1978.

Dai, Qiang and Kenneth J. Singleton, 2002, "Expectation Puzzles, Time-varying Risk Premia, and Affine Models of the Term Structure," Journal of Financial Economics, Vol. $63,415-441$.

Driessen, Joost, 2005, "Is Default Event Risk Priced in Corporate Bonds?," Review of Financial Studies, Vol. 18, No. 1, 165-195.

Duffee, Gregory R., 1999, "Estimating the Price of Default Risk," Review of Financial Studies, Vol. 12, 197-226.

Duffee, Gregory R., 2002, "Term Premia and Interest Rate Forecasts in Affine Models," Journal of Finance, Vol. 57, 405-443.

Duffee, Gregory R., 2011, "Forecasting with the Term Structure: The Role of No-Arbitrage," Manuscript, Johns Hopkins University. 
Duffie, Darrell and Rui Kan, 1996, "A Yield-Factor Model of Interest Rates," Mathematical Finance, Vol. 6, 379-406.

Feldhütter, Peter and David Lando, 2008, "Decomposing Swap Spreads," Journal of Financial Economics, Vol. 88, 375-405.

Fisher, Mark and Christian Gilles, 1996, "Term Premia in Exponential-Affine Models of the Term Structure," Manuscript, Board of Governors of the Federal Reserve System.

Gürkaynak, Refet S., Brian Sack, and Jonathan H. Wright, 2007, "The U.S. Treasury Yield Curve: 1961 to the Present," Journal of Monetary Economics, Vol. 54, 2291-2304.

Hautsch, Nikolaus and Yangguoyi Ou, 2012, "Analyzing Interest Rate Risk: Stochastic Volatility in the Term Structure of Government Bond Yields," Journal of Banking and Finance, Vol. 36, 2988-3007.

Jacobs, Kris and Lofti Karoui, 2009, "Conditional Volatility in Affine Term Structure Models: Evidence from Treasury and Swap Markets," Journal of Financial Economics, Vol. 91, 288-318.

Jagannathan, Ravi, Andrew Kaplin, and Steve Sun, 2003, "An Evaluation of Multi-Factor CIR Models Using LIBOR, Swap Rates, and Cap and Swaption Prices," Journal of Econometrics, Vol. 116, No. 1-2, 113-146.

Koopman, Siem J., Max I. P. Mallee, and Michel van der Wel, 2010, "Analyzing the Term Structure of Interest Rates using the Dynamic Nelson-Siegel Model with Time-Varying Parameters," Journal of Business and Economic Statistics, Vol. 28, No. 3, 329-343.

Litterman, R., and J. A. Scheinkman, 1991, "Common Factors Affecting Bond Returns," Journal of Fixed Income, Vol. 1, 62-74.

Nelson, Charles R. and Andrew F. Siegel, 1987, "Parsimonious Modeling of Yield Curves," Journal of Business, Vol. 60, 473-489.

Williams, David, 1997, Probability with Martingales, Cambridge University Press. 